\title{
Individual-denoting classifiers
}

\author{
Mana Kobuchi-Philip
}

Published online: 7 August 2007

(C) Springer Science+Business Media B.V. 2007

\begin{abstract}
This paper discusses Japanese numeral quantifiers that are used to count individuals, rather than quantities of a substance, and which may occur either as floated or non-floated quantifiers. It is argued that such morphologically complex numeral quantifiers (NQs) are semantically complex as well: The numeral within the NQ is the quantifier itself, the classifier its domain of quantification. The proposed analysis offers a unified semantic account of floated and non-floated NQs that adheres closely to their surface morphology and syntax. It explains why floated NQs generally force a distributive reading. It covers both classifiers construed with objects and classifiers construed with events. In addition, it captures the fact that the classifier must agree with the NP it is construed with.
\end{abstract}

Keywords Classifier - Numeral $\cdot$ Floating quantifier $\cdot$ Atomicity condition · Distributivity

This paper derives from my CUNY thesis. I owe a great debt of gratitude to Bob Fiengo, Bill McClure, Marcel den Dikken, and Atsu Inoue for their guidance. I thank my fellow linguists for inspiring discussions on various issues related to this paper. For suggestions and valuable comments, I would also like to thank the audience at several conferences and meetings where parts of the material in this paper were presented. My profound gratitude for the present form of the paper goes to two anonymous reviewers as well as the NALS editors Angelika Kratzer and Irene Heim for truly constructive criticisms and suggestions. All shortcomings are mine.

M. Kobuchi-Philip ( $\square)$

UiL-OTS, Utrecht University,

Janskerkhof 13, 3512 BL Utrecht,

The Netherlands

e-mail: mana.kobuchi@let.uu.nl 


\section{Introduction}

The Japanese numeral quantifier is a complex expression, consisting of a numeral (Num) and a classifier $(\mathrm{Cl})$, i.e. $[\mathrm{Num}+\mathrm{Cl}]$. Numeral quantifiers (henceforth NQs) that are used to count individuals contain a classifier that expresses a general property of the individuals in question, e.g. nin 'person' in san-nin 'three people' or satsu 'volume' in san-satsu 'three volumes'. ${ }^{1}$ This kind of NQ can occur either within a nominal constituent, as a 'DP-local numeral quantifier' (DNQ), or in an adverb position, as a 'floated numeral quantifier' (FNQ). However, there is a significant semantic difference between the two, and this difference is the focus of this paper. As many authors have noted, an FNQ sentence generally forces a distributive reading (e.g. Terada 1990; Kitagawa and Kuroda 1992; Sasaki Alam 1997; Kato 1997; Ishii 1998; Nakanishi 2004). In contrast, a DNQ sentence readily allows a collective as well as a distributive reading. The minimal pair in (1) illustrates this semantic phenomenon. Here the NQ and the NP that it is construed with (henceforth 'host NP') are both boldfaced, and square brackets indicate a DP. ${ }^{2}$

(1)a. [futa-ri-no moto-dookyuusei]-ga sengetsu kekkonshita. (DNQ) 2-CL-GEN ex-classmate-NOM last month married

'Two ex-classmates got married last month (to each other/to two other people).'

b. [moto-dookyuusei]-ga sengetsu futa-ri Kekkonshita. (FNQ) ex-classmate-NOM last month 2-CL married

'Two ex-classmates each got married last month (*to each other/to two other people).'

The DNQ sentence in (1a) is true if two of the speaker's ex-classmates each got married to someone else (distributive reading), or if two of the speaker's ex-classmates got married to each other (collective reading). The FNQ sentence in (1b), on the other hand, is true only under the distributive reading; it cannot mean that the two ex-classmates married each other. This appears to be related to a general property of floated quantifiers (FQs). As many authors have noted, English and French FQ sentences also have an unmarked distributive interpretation (e.g. The students have all received \$2000.) (e.g. Hoeksema 1983; Roberts 1986; Link 1983, 1987; Junker 1990).

\footnotetext{
${ }^{1}$ Numeral quantifiers can be classified by the type of classifier they contain. In this paper we restrict our attention to numeral quantifiers of type (i):

(i) [Numeral + Individual Classifier] e.g. nin 'person', kumi 'group' kai 'time' etc.

(ii) [Numeral + Measure Classifier] e.g. rittoru 'liter', guramu 'gram', etc.

(iii) [Numeral + Monetary Classifier] e.g. en 'yen', doru 'dollar', etc.

(iv) [Numeral + Temporal Classifier] e.g. byoo 'second', nen 'year', etc.

(v) [Numeral + Degree Classifier] e.g. do ${ }^{\circ} \mathrm{C} /{ }^{\circ} \mathrm{F}$ ', jisoku kiro ' $\mathrm{km} / \mathrm{h}$ ', etc.
}

\footnotetext{
${ }^{2}$ Strictly speaking, the particle no in [NQ-no NP] in (1a) is probably not a genitive marker but rather an attributive form of the copula (Kuno 1973) or a 'linker' (Koike 1999, Den Dikken and Singhapreech 2005).
} 
However, the Japanese FNQ is distinct from FQs in languages like English in several respects. First, a Japanese FNQ contains a numeral, a weak quantifier. Second, it includes a classifier. Third, while FQs in languages like English are generally subject-oriented (putting aside special constructions like I saw them both), the host NP need not be the subject in Japanese. Object-oriented FNQs are just as productive as subject-oriented FNQs, and in some cases even the object of a PP can be the host NP:

$\begin{array}{llll}\text { (2)a. John-wa hon-o Asahiya-de, san-satsu katta. } & \text { bought } \\ & J-T O P \text { book-ACC Asahiya bookstore-at 3-CL } & \\ & \text { 'John bought three books at Asahiya bookstore.' } & \\ \text { b. } & \text { suieikyoogi-de orandajin-ga, go-shumoku } & \\ & \text { swimming event-in Dutch-NOM 5-CL } & \\ \text { kinmedaru-o totta. } & & \\ \text { gold medal-ACC won } & \end{array}$

'In swimming the Dutch won a gold medal in five events.'

Finally, unlike English FQs, Japanese FNQs can be event-related, provided they contain what I call an 'event classifier'. Such an FNQ sentence may entirely lack a host NP:

(3)a. John-ga pisutoru-o san-patsu utta.
J-NOM pistol-ACC 3-CL shot
'John shot three shots (of a pistol).'
b. John-wa sokode ni-kai tonda.
John-TOP there 2-CL jumped
'John jumped there twice.'

In (3a) the FNQ san-patsu 'three shots' can be indirectly related to the NP pisutoru 'pistol', but it is not construed with it. San-patsu certainly does not count pistols in (3a), since this sentence is just as true if John shot a single pistol three times. This absence of a host NP is the earmark of an event-related FNQ. ${ }^{3}$ In ( $3 \mathrm{~b}$ ) the FNQ ni-kai 'twice' is even more clearly eventrelated; it can only be construed with the predicate tonda 'jumped'.

\footnotetext{
${ }^{3}$ Two anonymous reviewers point out the use of hatsu in sentences like (i), where it appears to refer to objects:

(i)

$$
\begin{array}{llll}
\text { John-ga pisutoru-no tama-o } & \text { san-patsu } & \text { utta. } \\
\text { John-NOM pistol-GEN bullet-ACC } & \text { 3-CL } & \text { shot } \\
\text { 'John shot three pistol bullets.' } & &
\end{array}
$$

Such a sentence is perfectly felicitous, and the classifier hatsu seems to refer to bullets. However, in view of the fact that the Chinese character for hatsu essentially means explosion or sudden release, I speculate that this is either a derived meaning or an inference. Given that pistols normally shoot one bullet at a time, if three shots were fired, one can normally assume that three bullets flew out of the gun. Note also that (ii) would be perfectly well-formed if a pistol shot five bullets simultaneously each time it was shot, even though hatsu cannot possibly be referring to bullets in both clauses:
} 
To see how the Japanese FNQ relates to FQs in other languages, we must start by constructing a theory of the Japanese FNQ that captures its special properties. This is what I attempt to do in this paper. My proposal focuses on NQs that quantify over individuals (objects or events). It does not cover NQs that contain measure classifiers and that are used to count quantities of substances, e.g. san-bai-no biiru '3 glasses of beer'. It offers a unified semantic analysis of Japanese FNQs and DNQs that quantify over individuals. The central hypothesis is that the classifier restricts the domain of quantification (the first argument) for the numeral. The second argument is identified as the element that is syntactically composed with the NQ-the host NP in the case of the DNQ and the predicate in the case of the FNQ. The classifier is analyzed as denoting a set of just atoms (excluding sums) in the sense of Link (1983), thereby satisfying a basic logical prerequisite for counting (Kratzer 1989; Chierchia 1998a; Landman 2000). This 'atomicity' of the classifier denotation is identified as the source of the distributive reading in the case of FNQ sentences. The proposal accounts for the classifier-NP agreement phenomenon in terms of semantic selectional restrictions. The scope of this paper is strictly limited to the Japanese NQ. However, if the analysis is on the right track, it suggests a reconsideration of at least two general linguistic issues, i.e. (i) numeral quantification over individuals with and without a classifier, and (ii) the semantics of FQs in general.

Footnote 3 continued

(ii)

$$
\begin{aligned}
& \text { John-ga pisutoru-o ip-patsu utsu-to tama-ga go-hatsu tobidashita. } \\
& \text { John-NOM pistol-ACC 1-CL shot-then bullet-NOM 5-CL shot out }
\end{aligned}
$$

'Five bullets shot out as John shot a pistol once.'

As a reviewer points out, hatsu cannot refer to just any type of blast or explosion, as attested by (iii), but it can refer to other types of explosive or sudden events with NQs that are not counting objects, as illustrated in (iv)-(vi):

(iii) kinoo sono kazan-ga, $\left\{{ }^{*}\right.$ san-patsu/san-do/san-kai $\}$ bakuhatsushita. yesterday the volcano-NOM 3 -cl $l_{\text {blast }} / 3-C L_{\text {time }} / 3-C L_{\text {time }}$ exploded 'Yesterday the volcano exploded three times.'

(iv) John-wa senaka-ni shageki-o, ni-hatsu uke, yuka-ni kuzure-ochita. John-TOP back-in shot-ACC 2-CL receive floor-on collapse-fell 'John received two shots in the back and fell on the floor.'

(v) dono fune-mo kono misaki-de muteki-o ni-hatsu narasu. which ship- $Q$ this cape-at fog horn-ACC 2-CL sound 'Every ship sounds its fog horn twice at this cape.'

(vi) Hiroshi-wa Takeshi-no yokottsura-o ni-hatsu nagutta. Hiroshi-TOP Takeshi-GEN cheek-ACC 2-CL punched 'Hiroshi punched Takeshi in the jaw twice.' 
The paper is organized as follows. Sect. 2 provides evidence in support of the empirical claim that the Japanese FNQ is systematically assigned a distributive reading. Sect. 3 reviews the syntactic evidence that the Japanese FNQ is a predicate modifier in the verbal domain. In Sect. 4, I briefly discuss two approaches to the FQ in the prior literature. Sect. 5 presents my new analysis of the FNQ. Sect. 6 turns to the DNQ and shows that its ambiguity arises from the circumstance that its quantificational structure is distinct from that of the FNQ. Sect. 7 discusses the classifier-NP agreement phenomenon. Finally, Sect. 8 contains a summary of the proposal as well as a short discussion of its implications.

\section{The distributive reading of the Japanese FNQ}

I present here three types of data which support the empirical claim that a FNQ sentence generally requires a distributive reading: (i) FNQ sentences containing a once-only predicate; (ii) FNQ sentences in a discourse context that clashes with a distributive reading; and (iii) FNQ sentences containing a collective predicate.

Two points of clarification must be made before presenting the data. The first concerns the meaning of 'distributive reading'. In this paper this concept is defined strictly in terms of properties of individual objects (e.g. Bennett 1974), and not in terms of events or situations. ${ }^{4}$ The distributive reading of a sentence like Three boys built a raft is the reading under which each of three boys has the property of having built a raft all by himself, entailing that three different rafts were built. In contrast, the collective reading is the reading under which a group consisting of three boys has the property of having built a single raft, but no individual boy has this property. Note that simultaneous actions do not entail that a collective reading has been assigned. For example, Three boys built a raft together can be true when three boys each built a different raft at the same time and place. Thus, adverbs such as together and Japanese isshoni 'together' only specify that the actions of the individuals in question occur at the same time and place; however, they do not necessarily force a collective reading. This can be conjectured by the fact that together can co-occur with a lexically distributive predicate as in Three boys walked together. ${ }^{5}$ Under the property-based definition we are assuming, the collective reading can be observed in a sentence like Ten boys formed a circle around a campfire.

\footnotetext{
${ }^{4}$ In Sect. 5, I will consider how event quantification interacts with an FNQ containing an event classifier.

${ }^{5}$ To avoid confusion with the collective reading, we might call a situation that verifies a sentence like Three boys walked together a 'company reading'.
} 
Here the property of forming a circle can only be attributed to a group of boys; no individual boy can possibly have such a property.

The second point of clarification concerns the form of the DNQ sentence. Abstracting away from scrambling, the canonical FNQ sentence has the FNQ in a preverbal position. In written form, this can easily be mistaken for a type of DNQ sentence that has the same word order. For example, (4a) can either have the FNQ structural analysis shown in (4b) or the DNQ structural analysis shown in $(4 \mathrm{c})$.

$\begin{array}{lllll}\text { (4)a. } & \text { otoko-ga } & \text { san-nin } & \text { hon-o } & \text { katta. } \\ \text { man-NOM } & 3-C L & \text { book-ACC } & \text { bought } \\ \text { DP subj } & \text { NQ } & \text { DP }_{\text {obj }} & \text { V } \\ \text { 'Three men bought a book.' } & \\ \text { b. } & {[\mathrm{DP}-\mathrm{NOM}]\left[\mathrm{NQ}_{\text {subj }} \mathrm{VP}\right]} & (\mathrm{FNQ}) \\ \text { c. } & {\left[\mathrm{DP}-\mathrm{NOM} \mathrm{NQ}_{\text {subj }}\right][\mathrm{VP}]} & \text { (DNQ) }\end{array}$

In actual speech the two structural analyses are disambiguated by distinctive pitch patterns. ${ }^{6}$ It is important to bear this in mind because DNQ sentences of the type represented by (4c) do allow collective and cover readings. When presenting FNQ sentences, I will put a comma between the host NP and the FNQ to represent the disambiguating prosody.

The first kind of data are sentences that contain what is generally referred to as a 'once-only predicate'. These are predicates which denote an event that can only occur once in the actual world. Consider first the two DNQ sentences in (5).

(5)a. san-nin-no otoko-ga hibiyakooen-no baiten-de chizu-o katta. 3-CL-GEN man-NOM Hibiya park-GEN kiosk-at map-ACC bought 'Three men bought a map at the kiosk in Hibiya Park.'

b. san-nin-no otoko-ga hibiyakooen-no baiten-de

3-CL-GEN man-NOM Hibiya park-GEN kiosk-at

Tanaka-o koroshita.

Tanaka-ACC killed

'Three men killed Tanaka at the kiosk in Hibiya Park.'

Sentence (5a) has the iterative predicate chizu-o katta 'bought a map'. This DNQ sentence is ambiguous since it is true of any of the following three situations: (i) three men each bought a different map (distributive reading), (ii) three men bought a single map (collective reading), and (iii) two men bought one map together while the third man bought another map (cover reading). In contrast, the DNQ sentence in (5b), which contains the once-only predicate Tanaka-o koroshita 'killed Tanaka', cannot be felicitously assigned a

\footnotetext{
${ }^{6}$ If sentence (4a) is parsed as (4b), a pitch rise must occur on the NQ. In contrast, if (4a) is parsed as (4c), a pitch rise cannot occur on the NQ. As Selkirk and Tateishi (1991) have shown, a rise in pitch corresponds to a syntactic boundary in Japanese. In the case of (4b), the pitch rise observed on the NQ identifies its syntactic position at the left edge of a VP.
} 
distributive or cover reading since this would make it necessarily false in the actual world. (5b) is felicitous only under a collective reading. Now, consider the FNQ sentence in (6), which forms a minimal pair with (5b).

\#otoko-ga hibiyakooen-no baiten-de, san-nin
man-NOM Hibiya park-GEN kiosk-at $3-C L$
Tanaka-o koroshita.
Tanaka-ACC killed
'Three men each killed Tanaka at the kiosk in Hibiya Park.'

This sentence is pragmatically ill-formed. ${ }^{7}$ In order to be felicitous, a collective reading must be assigned to it, yet such reading is not available. ${ }^{8}$ The only proposition that (6) can assert is a proposition which entails that Tanaka died three times. Despite a strong pragmatic need for a collective reading, only a distributive reading can be assigned to the FNQ sentence in (6).

Next, let us look at how an FNQ sentence contributes to discourse coherence. Consider the coherent discourse fragment consisting of (7a) followed by (7c), and compare it with the incoherent discourse fragment consisting of (7b) followed by $(7 \mathrm{c})$.

(7)a. futa-ri-no butsurigakusha-ga sono genshoo-ni tsuite
$2-C L-G E N$ physicist-NOM the phenomenon-to pertaining
atarashii riron-o happyooshita.
new theory-ACC presented
'Two physicists presented a new theory about the phenomenon.'
b. butsurigakusha-ga sono genshoo-ni tsuite, futa-ri
physicist-NOM phenomenon-to pertaining 2-CL
atarashii riron-o the happyooshita.
new theory-ACC presented
'Two physicists each presented a new theory about the phenomenon.'
hito-ri-ga sono riron-no zenhan-o happyooshi moo
1-CL-TOP the theory-GEN first half- $A C C$ present another
hito-ri-ga koohan-o happyooshita.
1-CL-NOM second half- $A C C$ presented

'One presented the first half of the theory and the other the second half.'

\footnotetext{
${ }^{7}$ In this paper, I use the term '(semantically or pragmatically) ill-formed' or 'infelicitous' in order to distinguish this type of ill-formedness from syntactic ungrammaticality.

${ }^{8}$ A reviewer points out that this type of sentence becomes acceptable if the verb is changed to the progressive form. For example, consider (i) from Nakanishi (2004):

(i) John-wa [gootoo-ga sokode, san-nin Mary-o koroshi-tei-ta]-to itta. J-TOP robber-NOM there 3-CL M-ACC kill-PROG-PAST-COMP said

'John said that three robbers were killing Mary over there.'

This sentence is indeed perfectly acceptable; however, it remains distributive. Thanks to the imperfective aspect, subevents of being in the process of killing Mary are distributed over three robbers. An English sentence like Two men were each killing Mary is also felicitous, and for the same reason. In contrast, Two men each killed Mary is just as pragmatically ill-formed as (6) because it entails that Mary died twice.
} 
The DNQ sentence (7a) can be interpreted as stating either (i) that two physicists together presented one new theory (one theory, collective reading) or (ii) that they each individually presented their own new theory (two theories, distributive reading). ${ }^{9}$ However, sentence (7c) presupposes the existence of only one theory. Thus, a collective reading must be assigned to (7a) for the discourse fragment (7a)-(7c) to be coherent. In contrast, the discourse fragment (7b)-(7c) is incoherent due to a presupposition failure: (7b) asserts the existence of two theories, one for each physicist, but (7c) presupposes the existence of only one theory. This arises because the FNQ sentence in $(7 b)$ allows only a distributive reading.

Finally, let us look at sentences with a collective predicate. Consider first the contrast between the DNQ sentence in (8a) and the corresponding subject-oriented FNQ sentence in (8b):

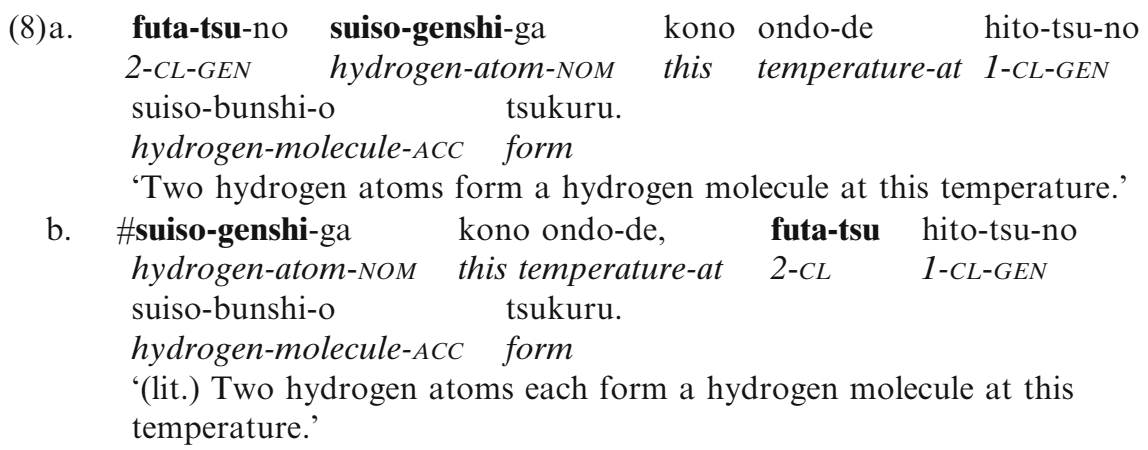

In the actual world, the only way for two hydrogen atoms to form a single molecule is by collectively participating in its creation. Thus, (8a) is true (or false) thanks to the availability of a collective reading. (8b), on the other hand, yields only the odd proposition that two hydrogen atoms each formed a single hydrogen molecule. Again, this is so because a collective reading is not available. The same effect can be observed with an object-oriented FNQ as well:

(9)a. bokushi-ga futa-ri-no kyookaiin-o
minister-NOM 2-CL-GEN church member-ACC
'The minister married two church members.'
b.
bokushi-ga kyookaiin-o, futa-ri kekkon saseta.
minister-NOM church member-ACC 2-CL married
'The minister married each of two church members.'

The DNQ sentence in (9a) can be interpreted either as (i) the minister married two church members to each other (collective) or as (ii) the minister married two

\footnotetext{
${ }^{9}$ In the remainder of this section, I will abstract away from the cover reading since it is only available when a collective reading is also available. 
church members, each one to some other person (distributive). The FNQ sentence in (9b) is a perfectly grammatical sentence; however, a collective reading of (9a) is not available. This sentence cannot mean that the minister married two people to each other. Once again we find that an FNQ sentence must be assigned a distributive reading, whether it is subject-oriented or object-oriented.

Having discussed the general incompatibility of FNQs with a collective reading, let us now consider some apparent counterevidence to this empirical generalization. Consider the FNQ sentences in (10), which are perfectly wellformed despite the presence of a collective predicate.

(10)a. gakusei-ga, gojuu-nin atsumatta.

student-NOM 50-CL gathered

'Fifty students gathered.'

b. John-ga sara-o, juu-mai kasaneta.

John-NOM plate-ACC 10-CL piled up

'John piled up ten plates.'

On closer examination, though, the interpretation of the sentences in (10) can be likened to that of (11):

$$
\begin{array}{ll}
\text { ame-ga, senshuu, sanbyaku-miririttoru } & \text { futta. } \\
\text { rain-NOM last week } 300-\mathrm{ml} & \text { fell } \\
\text { '300 ml of rain fell last week.' } &
\end{array}
$$

This is a sentence with a floated numeral quantifier but it does not quantify over individuals. The classifier denotes a measure function and the numeral quantifier functions as an amount term. In this case, neither a distributive nor a collective reading is available because we are not counting things but rather measuring a quantity of a substance. In (11), ' $300 \mathrm{mls}$ of rain' is not interpreted as 300 individual rain objects with the milliliter property, nor as a group of 300 rain objects that has this property. Rather, the unit expression $m l$ denotes a measurement scale and the numeral 300 refers to the size of an interval on that scale (Krifka 1990; Schwarzschild and Wilkinson 2002). To paraphrase Parsons (1970), the amount of rainwater referred to in (11) is taken as a single mass entity that can be measured out as 300 on the milliliter scale (300 milliliters' worth). What I propose, then, is that the same kind of interpretation is being assigned to the sentence in (10): (10a) asserts that the quantity of students, taken as a single mass entity, can be measured out as 50 on the 'nin-scale', and (10b) asserts that the quantity of plates, taken as a single mass entity, can be measured out as 10 on the 'mai-scale'. Because of the availability of this alternative amount term reading, the sentences in (10) are perfectly well-formed.

This is an instance of the count-mass shift discussed by Lønning (1987). In the default case, classifiers such as nin 'people' and mai 'sheets' are only used to count discrete objects, while classifiers such as miriguramu 'milligrams' and rittoru 'liters' denote a scale to measure the quantity of a given mass entity. Yet, under certain special circumstances, the classifier meaning can shift. This seems to be conditioned by the lexical semantics of the predicate. The 
collective predicates in (10), i.e. gathering and piling up, denote events that can in principle be measured out in terms of some degree or other. This contrasts with the kind of collective predicate illustrated in (8) and (9) above. There are no degrees of forming a hydrogen molecule or of being married. Thus, I do not consider observations like (10) a challenge to the empirical generalization established by the other facts presented above.

In sum, in this section we have seen that, in the unmarked case, when the numeral quantifies over individuals the FNQ sentence can only have a distributive reading while the DNQ sentence can have either a distributive, a collective, or a cover reading.

\section{The FNQ as a predicate modifier}

Before considering the semantics of the Japanese FNQ, we must first examine its syntax. In this section I briefly review two particularly strong pieces of evidence in support of the empirical claim that the FNQ has the syntax of a predicate modifier. ${ }^{10}$

The first noteworthy piece of evidence is that an FNQ can coordinate with an adverb, as illustrated in (12) (Fukushima 1991):

(12)a. shoonin-ga, [san-nin] katsu [tashikani] sono jiko-o
witness-NOM 3-CL and certainly the accident-ACC
mokugekishita
witnessed.
'Three witnesses witnessed the accident for certain.'
bary-ga raamen-o, $\quad$ [san-bai] katsu [kireini] tairageta.
Mary-NOM ramen noodle- $A C C \quad 3-C L \quad$ and cleanly ate up
'Mary ate up three bowls of ramen noodles completely.'

This strongly suggests that the FNQ itself is an adverb. If this were not the case, it is unclear how such sentences could be generated at all, given the

\footnotetext{
${ }^{10}$ The semantic difference between the DNQ and the FNQ discussed in the previous section is, of course, itself prima facie evidence of a syntactic distinction. See also Nakanishi (2004) for yet another semantic contrast observed between the DNQ and the FNQ, namely that the DNQ must satisfy a monotonicity constraint in the nominal domain while the FNQ need not.
} 
universal prohibition against coordinating expressions of distinct grammatical function..$^{11}$ In particular, it seems impossible to derive the FNQs in (12a) or (12b) from underlying DNQs. ${ }^{12}$

The second piece of strong evidence is the observation that FNQs of different types correlate syntactically with adverbs of different types in VP-clefting phenomena. Consider (13) and (14) (Nakayama and Koizumi 1991; Fujita 1994):

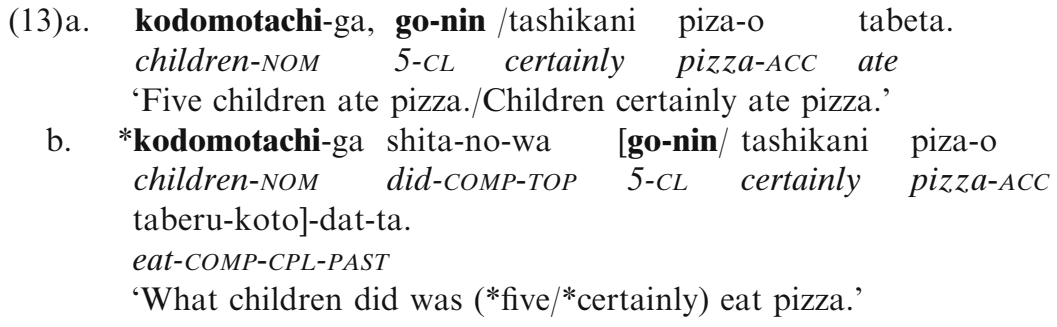

(14)a. John-ga piza-o, ni-mai /isoide tabeta.
John-NOM pizza-ACC $2-C L \quad$ hurriedly ate
'John ate two slices of pizza./ John ate pizza in a hurry.'

\begin{abstract}
${ }^{11}$ Violating this constraint gives rise to a type of ill-formedness known as 'zeugma' (Lyons 1977: 405). Generally this constraint also prohibits the coordination of expressions of distinct syntactic category, viz. $\left.{ }^{*}\left[[\text { every boy }]_{\mathrm{DP}} \text { and [quickly }\right]_{\mathrm{AdvP}}\right]$. In the case of adverbs, though, this latter, more stringent effect does not always hold, viz. [[quickly $]_{\mathrm{AdvP}}$ and [without hesitation $\left.]_{\mathrm{PP}}\right]$.

${ }^{12}$ According to a stranding-theoretical analysis (Sportiche 1988), the FNQ in (12a) would derive from something like $\left.*\left[[\text { shoonin san-nin }]_{\text {DP }} \text { katsu [tashikani }\right]_{\text {Adv }}\right]$ 'three witnesses and certainly'. Aside from the fact that this hypothetical underlying form would itself violate the general constraint on coordination, given that coordinated DPs form a syntactic island, it ought to be impossible to extract shoonin. An additional problem is that katsu cannot coordinate DPs to mean "and": the subject of (i) can only mean 'a student plumber', not 'a student and a plumber'; and (ii) is quite odd with katsu.
\end{abstract}

(i) gakusei katsu suidooya-ga kita.
student and plumber-NOM came
'A student plumber came.'

$$
\begin{aligned}
& \text { go-nin-no gakusei-to/\#katsu yo-nin-no sensei-ga yakyuuchiimu-o tsukutta. } \\
& 5 \text {-CL-GEN } \text { student and/and } 4 \text { - } C L-G E N \text { teacher-NOM baseball-team-ACC formed } \\
& \text { 'Five students and four teachers formed a baseball team.' }
\end{aligned}
$$

Note incidentally that English and Japanese contrast sharply as regards the coordination of adverbs and floated quantifiers, as can be seen from (iii), whereas such coordination is in principle possible in Dutch, as illustrated by (iv) (Hoeksema 1996):

(iii) *The planks were all and roughly chopped in half.

(iv) De kinderen hebben allemaal en binnen 14 dagen het diploma gehaald. The children have all and within 14 days the diploma earned 'The children all earned the diploma within 14 days.' 


\section{b. John-ga shita-no-wa [piza-o, ni-mai /isoide \\ John-NOM did-COMP-TOP pizza-ACC 2-CL hurriedly} taberu-koto]-da-tta.

eat-COMP-CPL-PAST

'What John did was eat two slices of pizza./ What John did was eat pizza in a hurry.'

As the ungrammaticality of (13b) attests, neither a subject-oriented FNQ nor a sentential adverb can be part of a VP-cleft related to the sentence in (13a). On the other hand, as shown by the grammaticality of (14b), both an objectoriented FNQ and a manner adverb can be part of a VP-cleft related to the sentence in (14a). These distributional correlations suggest not only that FNQs are intrinsically adverbs base-generated in adverb positions, but also that there are two syntactically distinct types of FNQs, each corresponding to a syntactically distinct type of adverb. Again, it is very hard to see how any syntactic derivation of FNQs from underlying DNQs could capture this correlation in a principled fashion.

There are other empirical facts that suggest the adverbial nature of FNQs; for example, a number of perfectly grammatical FNQ sentences with an event classifier do not seem to have a corresponding DNQ sentence (consider e.g. (3b) above, and (vi) in fn. 3). In view of this set of facts, I will henceforth assume that the FNQ has the syntax of a predicate modifier. In addition, I will assume that the FNQ syntactically forms its own maximal projection, that it can scramble as easily as any adverb, but that, when it scrambles, it can only be semantically interpreted by being reconstructed back into its original prescrambled position. The reason for this last assumption is that scrambled and non-scrambled FNQ sentences have identical truth conditions. ${ }^{13,14}$ For example, the scrambled FNQ sentence in (15) is just as ill-formed as the unscrambled sentence it derives from, due to the unavailability of a collective reading:

$$
\begin{array}{lllll}
\text { \#san-nin, } & \text { hibiyakooen-de } & \text { otoko-ga } & \text { Tanaka-o } & \text { koroshita. } \\
\text { 3-CL } & \text { Hibiya park-at } & \text { man-NOM } & \text { Tanaka-ACC } & \text { killed }
\end{array}
$$

'Three men each killed Tanaka in Hibiya Park.'

Let us now briefly look at the syntax of the DNQ. Each sentence in (16) illustrates a syntactically distinct type of DNQ.

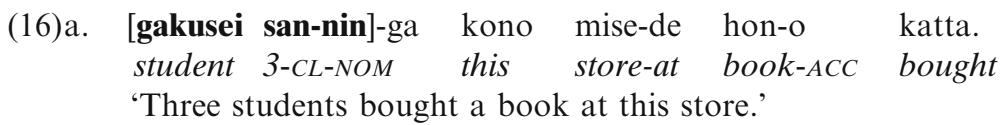

\footnotetext{
${ }^{13}$ According to Lasnik and Saito (1992), all scrambled material reconstructs at LF.

${ }^{14}$ In addition, scrambled and unscrambled FNQs have the same scopal interactions with other scope-taking expressions, while this is not the case for DNQs (Hasegawa 1991). 


$\begin{array}{llllll}\text { b. [gakusei-no san-nin]-ga kono mise-de hon-o } & \text { katta. } \\ \text { student-GEN } 3-C L-N O M & \text { this store-at book-ACC } & \text { bought } \\ \text { 'Three of the students bought a book at this store.' } & \\ \text { c. [san-nin-no gakusei]-ga kono mise-de hon-o } & \text { katta. } \\ \text { 3-CL-GEN student-NOM this store-at book-ACC } & \text { bought } \\ \text { 'Three students bought a book at this store.' } & \\ \text { d. [gakusei-ga san-nin], kono mise-de hon-o } & \text { katta. } \\ \text { student-NOM 3-CL this store-at book-ACC bought } \\ \text { 'Three students bought a book at this store.' } & \\ \text { e. [san-nin]-ga kono mise-de hon-o katta. } & \\ \text { 3-CL-NOM this store-at book-ACC bought } & \\ \text { 'Three people bought a book at this store.' } & \end{array}$

The DP-local nature of the NQs in (16a-c) is clear from the position of the nominative case marker $g a$. As for the form in (16d), although the exact nature of its internal structure is unclear, constituency tests such as conjunction and pseudoclefting demonstrate that [NP-Case NQ] is indeed a nominal constituent (Kamio 1983, Terada 1990). Thus, this NQ is clearly not part of the predicate but rather combines syntactically with the host NP. ${ }^{15}$ (16e) exemplifies the possibility of the occurrence of an NQ without an overt host NP. I assume that in such sentences, the host NP is covertly present, since Japanese is a so-called 'radical pro-drop language'. The reference of the covert host NP is provided by the context or inferred from the meaning of the classifier (e.g., hito 'people' for the classifier nin 'people').

Summing up, I assume the following basic constituent structures:
(17)a. Sentence with a subject-oriented DNQ:
$\left[\left[\mathrm{DNQ}_{\text {subj }} \mathrm{NP}\right] \mathrm{VP}\right]$
b. Sentence with an object-oriented DNQ:
$\left[D P\left[\left[D N Q_{o b j} N P\right]\right.\right.$ V]]
c. Sentence with a subject-oriented FNQ:
[DP [FNQ $\left.\mathrm{Fubj}_{\mathrm{sP}} \mathrm{VP}\right]$
d. Sentence with an object-oriented FNQ:
[DP [DP [FNQ obj $\mathrm{V}]]]$

The DNQ immediately forms a constituent with the host NP, as shown in $(17 \mathrm{a}-\mathrm{b})$. The FNQ immediately forms a constituent with the predicate, as

\footnotetext{
${ }^{15}$ Terada (1990) analyses [NP-Case NQ] as a QP; Kitahara (1992) treats it as a DP, and Koizumi (1995) proposes that it is a residual IP. Since all of these accounts have both theoretical and empirical problems (see e.g. Kobuchi-Philip 2003a), the precise syntactic nature of this NQ remains unclear. However, since the general consensus is that [NP-Case NQ] forms a constituent, I classify it as a type of DNQ.
} 
shown in (17c-d). The subject-oriented FNQ forms a constituent with the VP while the object-oriented FNQ forms a constituent with the verb. ${ }^{16}$

\section{Previous analyses}

From a semantic perspective, prior quantificational analyses of the FQ and the Japanese FNQ can be classified under two general quantificational approaches. ${ }^{17}$ Simplifying considerably, under one general approach, the FQ/ FNQ makes an assertion about the elements in the intersection of the set of objects denoted by the host NP and the set of objects denoted by the predicate (e.g. Dowty and Brodie 1984; Link 1987; Fukushima 1991). Under the other approach, the $\mathrm{FQ} / \mathrm{FNQ}$ makes an assertion about the quantity of events that are each related to objects denoted by the host NP (e.g. Junker 1990; Gunji and Hasida 1998; Nakanishi 2004). Informally, given an FNQ sentence such as (18a), the two approaches predict the truth conditions paraphrased in (18b):

$\begin{array}{ll}\text { (18)a. } & \text { gakusei-ga, san-nin hashitta. } \\ \text { student-NOM 3-CL } & \text { ran } \\ \text { 'Three students ran.' } & \end{array}$

\footnotetext{
in (i):

(i) *gakusei-ga CD-o, huta-ri katta. student-NOM CD-ACC 2-CL bought

'Two students bought a CD.'

(Saito 1985)
}

${ }^{16}$ Here I wish to add a brief comment on one of the classic puzzles posed by the Japanese FNQ, pointed out by a reviewer, namely the alleged ungrammaticality of the sentence type exemplified

Because this type of sentence is generally not acceptable, it has widely been assumed that the word order [S O FNQ $\left.\mathrm{Subj}_{\mathrm{V}} \mathrm{V}\right]$ leads to ungrammaticality. However, a number of counterexamples have been noted in the literature, e.g. the following:

watashi-wa imamadeni Metropolitan-no auction-de nihonjin-ga Goch-no e-o, 3-nin rakusatsushita-to kiita.

(Kawashima and Kitahara 1993) 'I heard that up to now, three Japanese bid successfully for paintings by van Gogh at the Metropolitan Auction.'

(iii) gakusei-ga sono henna nomimono-o, 3-nin chuumonshita. 'Three students ordered the strange drinks.'

(Fukushima 1991)

nadakoo-no seito-ga kotoshi toodai-o, 80-nin jukenshita.

(Takami 1998) ' 80 Nada high school students took the entrance exam of Tokyo University this year.'

The grammaticality of these sentences clearly demonstrates that the source of the ill-formedness of (i) is not purely the word order. Generally, this word order is assumed to arise from scrambling of the direct object (presumably to a VP-adjoined position). My speculation here is that the wellformedness of such a sentence is directly governed by the legitimacy of scrambling the direct object in the first place, rather than by any word order constraints specific to the FNQ.

${ }^{17}$ A third approach is that of Brisson (1998), who argues that the English FQ all does not quantify over objects but rather adjusts the truth conditions of the sentence relative to possible alternatives in the context. 
b. First Approach:

'There were three \{students who ran/runners who were students\}.'

Second Approach:

'There were three running events by a student.'

The first approach faces a difficulty in capturing the occurrence of an FNQ in sentences like (3), repeated here for convenience:

(19)a. pisutoru-ga, san-patsu utareta.

pistol-NOM 3-CL shot was shot

(lit) 'A pistol was shot three shots.'

b. John-wa sokode, ni-kai tonda.

John-TOP there 2-CL jumped

'John jumped twice there.'

These FNQs are event-related because the classifiers they contain are 'event classifiers'. In (3a), the intersection of the denotation of the NP pisutoru 'pistol' and the denotation of the predicate utareta 'was shot' must be a set of pistols which were shot. However, as noted earlier, the number of pistols is totally irrelevant to the truth or falsity of (3a). Rather, the numeral 3 counts the number of shots or blasts that occurred. Even more problematic for this approach is (3b), which completely lacks a host NP for the FNQ to be construed with. The existence of event classifiers in a classifier language should come as no surprise since all languages have nouns that denote types of events and such nouns are readily used to count and quantify over events (e.g., five sneezes, five kicks, five shots, five visits, and both shots, most shots, each shot, etc.). Some other examples of Japanese event classifiers are: (shown with a numeral) ichi-do 'one time', ik-kai 'one time', is-shuu 'one round', ik-kyoku 'one match (for shoogi or igo games)' ip-paku 'one overnight stay', ichioofuku 'one round trip' ik-kaiten 'one turn', is-shoo 'one win', ip-pai 'one losing'. There are also many more which derive from verb stems (the so-called renyoo form), such as hito-maki 'one roll', hito-mawari 'one round', hito-oshi 'one push', hito-keri 'one kick', hito-furi 'one swing', etc. ${ }^{18}$ When composed with an event classifier, a numeral counts events of the type specified by the classifier, rather than objects. It quantifies over event-individuals rather than object-individuals. Thus, the host NP is not required for the quantification computation. But now, if the host NP is not needed for FNQs like san-patsu

\footnotetext{
${ }^{18}$-Kai 'time' and -do 'time' are generic event classifiers which sometimes can be used instead of more specific classifiers:
}

(i) kinoo-no shiai-de Ichiroo-ga, san-toorui shita. yesterday-GEN game-in Ichiroo-NOM 3-CL did 'Ichiroo made three steals in yesterday's baseball game.'

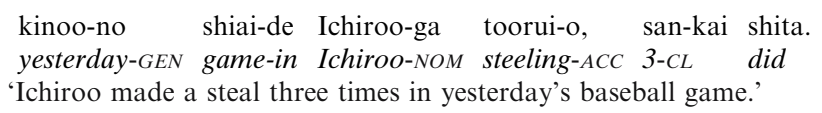


'three shots', which quantify over event-individuals, then perhaps it is also not needed for the quantification computation of FNQs like san-nin 'three people', which quantify over object-individuals. Indeed, if we wish to develop a unified account of FNQs, we must assume that the host NP plays no essential role in the semantic interpretation of either type of FNQ.

The second general approach to a semantic analysis of FNQs neutralizes the distinction between quantifying over objects and quantify over events by hypothesizing that all FNQs quantify over events. For example, in the most clearly formulated theory of this type, Nakanishi (2004) argues that the Japanese FNQ is subject to Schwarzschild's (2002) 'monotonicity constraint' in the verbal domain with respect to events. Adopting Krifka's (1989) analysis of the measure function, Nakanishi proposes a special homomorphic mapping mechanism $h$ from events to individuals. Equipped with this, the Japanese FNQ indirectly measures events by measuring individuals, as schematically shown in (19), where the objects which the FNQ refers to correspond to I:

(19) A measure function associated with an FNQ:

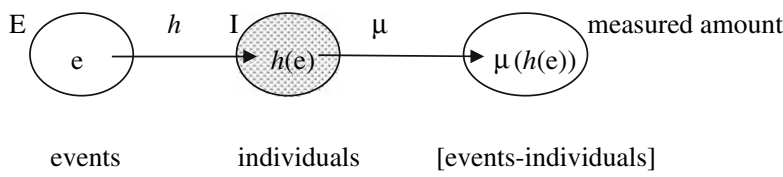

The homomorphism $h$ from events to individuals is a function which preserves structure, in particular, the property of cumulativity. In this theory, this is the mechanism which yields the distributive reading of the FNQ sentence. Because it is a homomorphism, events and individuals stand in a one-to-one relation, which systematically brings about a distributive reading. This is an elegant proposal, and Nakanishi's observations and analysis of DNQs and FNQs that function as amount terms, e.g. san-ton-no yuki 'three tons of snow', are clearly insightful. However, when it comes to FNQs that quantify over individuals, it is not certain how well this analysis applies to them. This is because it is unclear what the necessary and sufficient conditions are for the hypothesized homomorphism $h$ to arise. It cannot be claimed that it obligatorily arises with all FNQs, for this would falsely predict that sentences like gakusei-ga, 50-nin atsumatta 'Fifty students gathered' are just as ill-formed as sentences like \#otoko-ga, san-nin Tanaka-o koroshita 'Three men killed Tanaka'. Nor can it be claimed that $h$ optionally arises, for then the systematic distributive reading of FNQ sentences is not captured.

\section{FNQ quantification}

I present here an alternative analysis of quantification for the Japanese FNQ, based on a new identification of the three components of quantification, given the basic logical structure shown in (20) (e.g. Heim 1982). 
(20)

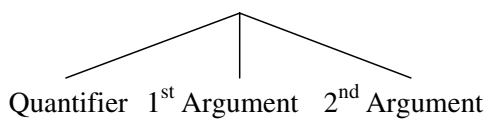

The proposed analysis derives the obligatory distributivity of the FNQ from the atomicity of the classifier.

\subsection{The three components of FNQs}

A simple FNQ sentence of the canonical type, such as (21a), has the sentence structure represented in $(21 b)$ :

(21)a.

$$
\begin{aligned}
& \text { gakusei-ga, san-nin kaetta. } \\
& \begin{array}{l}
\text { student-NOM 3-CL people } \\
\text { 'Three students left.' }
\end{array}
\end{aligned}
$$

I propose that the three quantificational components of the FNQ are as shown in (22) and that the denotations of the numeral and the classifier are as shown in (23) and (24), respectively:

$$
\begin{array}{ll}
\text { Quantifier: } & \text { Numeral } \\
1^{\text {st }} \text { Argument: } & \text { Classifier } \\
2^{\text {nd }} \text { Argument: } & \text { Predicate }
\end{array}
$$

$$
\text { Numeral: } \quad \begin{aligned}
\mathrm{n}_{\mathrm{NUM}}= & \lambda \mathrm{C} \lambda \mathrm{P} \lambda \mathrm{x} \exists \mathrm{K}[\mathrm{K} \subseteq(\mathrm{C} \cap \mathrm{P}) \wedge|\mathrm{K}|=\mathrm{n} \wedge \oplus \mathrm{K} \Pi \mathrm{x}] \\
& \text { where } \mathrm{C}=\text { classifier and } \mathrm{P}=\text { predicate }
\end{aligned}
$$

Classifier:

a. Object classifier: e.g. nin $\left(\mathrm{CL}_{\text {person }}\right)=\lambda \mathrm{x}_{\mathrm{e}}\left[\mathrm{NIN}_{\mathrm{AT}}(\mathrm{x})\right]={ }_{\text {abbr. }} \mathrm{NIN}_{\mathrm{AT}}$

b. Event classifier: e.g. hatsu $\left(\mathrm{CL}_{\mathrm{shot}}\right)=\lambda \mathrm{e}_{\mathrm{S}}\left[\operatorname{HATSU}_{\mathrm{AT}}(\mathrm{e})\right]={ }_{\text {abbr. }} \operatorname{HATSU}_{\mathrm{AT}}$ where AT stands for atom.

The unusual properties of this proposal are the following: First, the numeral and the classifier are treated as separate and independent semantic entities. The quantifier is the numeral alone and the classifier is its domain of quantification. Second, the classifier is treated as a (nominal) predicate that denotes a set of only atomic individuals, either objects or events. Third, the three components of FNQ quantification are contained entirely within the verbal domain, excluding the host NP. The first and the second aspect of the analysis are each empirically motivated, as I will show below. The third aspect is a logical consequence of the first, given the syntax of the FNQ, discussed in Sect. 3. For the purpose of this paper, the most significant consequence of this new analysis is that it explains why FNQ sentences systematically yield a distributive reading. The predicate denotation intersects with the classifier denotation. Since the classifier denotation is atomic this intersection must also 
be atomic, yielding distributivity. Now let us turn to the motivation for this proposal.

First, the claim that the quantifier is the numeral alone and that its first argument (domain of quantification) is the classifier is motivated by the simple observation that the numeral counts the individuals referred to by the classifier. The following minimal pairs demonstrate this:

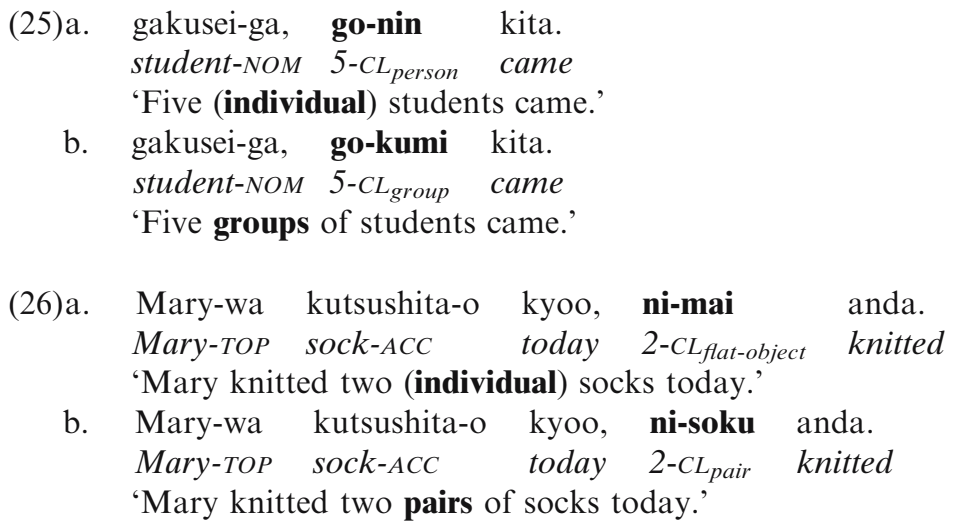

The a-sentences and the b-sentences have different truth conditions. For (25a) to be true, the number of people must be five, while for $(25 \mathrm{~b})$ to be true, the number of groups must be five. For (26a) to be true, the number of flat objects (socks here) must be two; for (26b) to be true, the number of pairs must be two (i.e. four socks). Minimal pairs such as these demonstrate that the classifier has a semantic value of its own. The classifier refers to a kind of superordinate object property, and the numeral counts objects that have this

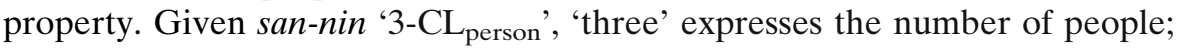
given san-mai ' $3-\mathrm{CL}_{\text {flat object }}$, 'three' expresses the number of flat objects; and so on. ${ }^{19}$

Second, that the classifier must denote a set of only atomic individuals follows from a basic principle of the logic of counting, namely that, in order to be countable, an entity be discrete (Kratzer 1989; Chierchia 1998a; Landman 2000). While the Japanese noun denotation can be argued to consist of both 'atoms' and 'sums' under Link's (1983) theory of plurality, the classifier

${ }^{19}$ The meanings of words such as those shown below indicate that what the classifier refers to is countable:
(i) nin-zuu
$C L_{\text {person-number }}$

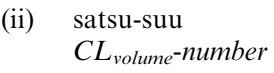
'number of volumes'
(iii) ko-suu
$C L_{\text {piece-number }}$
'number of pieces'


denotation must contain only atoms..$^{20,21}$ If a classifier denotation included sums, its denotation would be as shown in (27), for a context in which there were four people, a, b, c, and d:

$$
\text { nin: } \begin{aligned}
\mathrm{CL}_{\text {person }}= & \{\mathrm{a} \oplus \mathrm{b} \oplus \mathrm{c} \oplus \mathrm{d}, \mathrm{a} \oplus \mathrm{b} \oplus \mathrm{c}, \mathrm{a} \oplus \mathrm{b} \oplus \mathrm{d}, \mathrm{a} \oplus \mathrm{c} \oplus \mathrm{d}, \mathrm{b} \oplus \mathrm{c} \oplus \mathrm{d}, \\
& \mathrm{a} \oplus \mathrm{b}, \mathrm{a} \oplus \mathrm{c}, \mathrm{a} \oplus \mathrm{d}, \mathrm{b} \oplus \mathrm{c}, \mathrm{b} \oplus \mathrm{d}, \mathrm{c} \oplus \mathrm{d}, \mathrm{a}, \mathrm{b}, \mathrm{c}, \mathrm{d}\}
\end{aligned}
$$

For an NQ such as san-nin '3 persons', three elements must be selected from (27). Thus, the selections represented in (28a) and (28b) could in principle be possible:

(28)a. $\quad\{\mathrm{a} \oplus \mathrm{b} \oplus \mathrm{c} \oplus \mathrm{d}, \mathrm{a}, \mathrm{c}\} \quad$ b. $\quad\{\mathrm{a} \oplus \mathrm{c}, \mathrm{a}, \mathrm{c}\}$

Both in (28a) and in (28b) the number of counted elements is indeed three; however, in (28a) the number of people is as many as four, namely a, b, c, and d. Worse, in (28b) it is now only two, namely, a and c. This is worse because, while the sentence 'Three people left' would not be entirely false if four people left, as in (28a), this sentence is necessarily false if only two people left, as in (28b). The problem here arises precisely from counting sums as well as atoms. In order to count correctly, the domain of quantification must not include sums, i.e. the classifier denotation must consist of just atoms, as shown in (29):

$$
\text { nin: } \mathrm{CL}_{\text {person }}=\{\mathrm{a}, \mathrm{b}, \mathrm{c}, \mathrm{d}\}
$$

As for the type of the classifier, since each classifier is lexically determined to refer to object-individuals, e.g. nin (person), or to event-individuals, e.g. hatsu (explosion), the two types of individuals must be distinguished. This can be formally implemented by defining event classifiers as of type $<\mathrm{s}, \mathrm{t}>$ and object classifiers as of type $<\mathrm{e}, \mathrm{t}>$.

Third, counter to a general assumption in the literature, under the proposed analysis the three components of quantification are entirely contained within the verbal domain. This is a logical consequence of the claim that the FNQ, which is a predicate modifier, consists of a quantifier and its domain of quantification, with the predicate serving as the second argument. That the predicate functions as the second argument can be demonstrated by the interpretation of the following complex type of FNQ sentence, which contains both a DNQ and an FNQ:

\footnotetext{
${ }^{20}$ Whether or not the denotation of an English plural term should include the atoms is a matter of controversy (see e.g. Hoeksema 1983; Lasersohn 1988; Schwarzschild 1990; Chierchia 1998b; Landman 2000). However, given that an object-denoting noun such as gakusei 'student' can always be interpreted as singular or plural, I assume the Japanese noun denotation contains both atoms and sums (see discussion below).

${ }^{21}$ See Kang (1994) for a similar argument with respect to Korean noun denotation.
} 
(30)
[narande hashitteita
suu-dai-no
torakku]-ga,
san-dai
in a row running
several-CL-GEN
truck-NOM
$3-C L$
gaadoreeru-ni butsukatta
guardrail-to hit.
(Inoue 1978)
'Three of the several trucks that were driving in tandem hit the guardrail.'

When a DNQ and an FNQ co-occur in a single sentence, it generally yields a partitive reading, with the DNQ and the FNQ corresponding to the whole and the part, respectively. ${ }^{22}$ In (30) the property of the FNQ 'three vehicles' is that they "hit the guardrail" (the property described by the predicate), and not that the three vehicles "are several trucks which were running in tandem" (the property described by the host NP). To be precise, three vehicles are only part of the several trucks which were running in tandem. This interpretation fact directly shows that the second argument of the numeral is the predicate. It follows that the three components of quantification are entirely contained within the verbal domain.

Having motivated the analysis, I'll now comment briefly on the status of the host NP. Typically, the predicate containing the FNQ composes with the host NP, often a simple bare noun such as gakusei 'student', hon 'book', or the like. Japanese NPs are systematically ambiguous between a definite and an indefinite reading (aside from the singular/plural underspecification). This fact can straightforwardly be captured by hypothesizing the presence of phonetically null indefinite/definite determiners. For example, a sentence like (31a) would be interpreted as shown in (31b) for the definite reading, or as in (31c) for the indefinite reading of gakusei 'student':

\section{(31)a. gakusei-ga kita.}

student-NOM came

'A/some/the student(s) came.'

b. $\quad \operatorname{KITA}(\oplus$ GAKUSEI $)$ with $\varnothing$ 'the': $\lambda \mathrm{X}_{<\mathrm{e}, \mathrm{t}>} \lambda \mathrm{Y}_{<\mathrm{e}, \mathrm{t}>}[\mathrm{Y}(\oplus \mathrm{X})]$ came student

\footnotetext{
${ }^{22}$ For this type of sentence to be felicitous, the numeral in the DNQ must be equal to or greater than that in the FNQ. If not, the sentence becomes anomalous:

(i)

$$
\begin{aligned}
& \text { \#san-nin-no gakusei-ga, go-nin peepaa-o kaita. } \\
& \text { 3-CL-GEN student-NOM 5-CL paper-ACC wrote } \\
& \text { (\# 'Five of the three students wrote a paper.') }
\end{aligned}
$$

If the numeral is the same in the DNQ and in the FNQ, the resulting redundancy gives rise to a slight ill-formedness that may be likened to that seen in an English sentence such as (ii) (Robert Fiengo, p.c.; Dowty and Brodie 1984):
}

(ii) ?All the students all wrote a paper.

Note that the following sentence with -tomo 'all' is totally acceptable and informative:

(iii) san-nin-no gakusei-ga, san-nin-tomo peepaa-o kaita. 3-CL-GEN student-NOM 3-CL-all paper-ACC wrote

'Three students all the three wrote a paper.' 
c. $\quad \exists y[\operatorname{Gakusei}(y) \wedge \operatorname{Kita}(y)]$ with $\varnothing$ 'a': $\lambda \mathrm{X}_{<\mathrm{e}, \mathrm{t}}>\lambda \mathrm{Y}_{<\mathrm{e}, \mathrm{t}}>\exists \mathrm{y}[\mathrm{X}(\mathrm{y}) \wedge \mathrm{Y}(\mathrm{y})]$ student came

With a definite determiner, gakusei 'student' refers to the supremum of the contextually relevant students (possibly an atom or a sum). With an indefinite determiner, the sentence asserts the presence of a single element in the set denoted by gakusei 'student' (possibly an atom or a sum). Thus, hypothesizing a null determiner accounts for the definite/indefinite ambiguity with extreme simplicity. Now, the host NP in an FNQ sentence would also be associated with a null determiner. In the unmarked case, in which an FNQ sentence yields a weak, existential reading, the associated null determiner is indefinite, while in the other case it is definite, yielding a partitive reading (recall (30)). Under this analysis, then, the host NP is indeed not part of the process of numeral quantification. The host NP is simply an argument of the predicate. This leaves unanswered a question regarding the agreement relation between the classifier within the FNQ and the host NP. I will discuss this matter in Sect. 7.

\subsection{Interpretation of the FNQ sentence}

Here I present the derivation of two simple FNQ sentences, one with a subject-oriented FNQ and the other with an object-oriented FNQ. We start with the former:

(32)a. [gakusei-ga, [san-nin] $[2 \mathrm{~km}$ oyoida]]. student-NOM 3-CL $2 \mathrm{~km}$ swam 'Three students swam 2 km.'

b. Lexical Entries: 3:

$$
\begin{aligned}
& \lambda \mathrm{C}_{<\mathrm{e}, \mathrm{t}>\lambda \mathrm{P}}<\mathrm{e}, \mathrm{t}>\lambda \mathrm{x}_{\mathrm{e}} \exists \mathrm{K}[\mathrm{K} \subseteq(\mathrm{C} \cap \mathrm{P}) \wedge \\
& \left.|\mathrm{K}|=3 \wedge \oplus \mathrm{K} \prod \mathrm{x}\right] \\
& \operatorname{nin} \text { 'nin(CL)': } \quad \mathrm{NIN}_{\mathrm{AT}} \\
& \text { gakusei 'student': } \quad \lambda \mathrm{x}_{\mathrm{e}} \text { [GAKUSEI(x)] }
\end{aligned}
$$$$
2 \mathrm{~km} \text { oyoida 'swam } 2 \mathrm{~km} \text { ': } \lambda \mathrm{x}_{\mathrm{e}}\left[2 \mathrm{KM} \text { OYOIDA(x)] }={ }_{\text {abbr. }} 2 \mathrm{KM}\right. \text { OYOIDA }
$$$$
\varnothing \text { 'a': } \quad \lambda \mathrm{X}_{<\mathrm{e}, \mathrm{t}}>\lambda \mathrm{Y}<\mathrm{e}, \mathrm{t}>\exists \mathrm{y}[\mathrm{X}(\mathrm{y}) \wedge \mathrm{Y}(\mathrm{y})]
$$

Outcome:

$\exists \mathrm{y}\left[\operatorname{GAKUSEI}(\mathrm{y}) \wedge \exists \mathrm{K}\left[\mathrm{K} \subseteq\left(\operatorname{NIN}_{\mathrm{AT}} \cap 2 \mathrm{KM}\right.\right.\right.$ OYOIDA $\left.\left.) \wedge|\mathrm{K}|=3 \wedge \oplus \mathrm{K} \prod \mathrm{y}\right]\right]$ student nin swam $2 \mathrm{~km}$

The final line of (32b) asserts that there is a set $\mathrm{K}$, a subset of the set of individual people who swam $2 \mathrm{~km}$, which has a cardinality of three and whose supremum is a (proper or improper) part of some element of the student set.

Informally, the verification process can be illustrated as follows: Imagine a model containing six individuals who swam across a lake that was 2 kilometers wide: $\mathrm{d}$, e, f, g, h, and $\uparrow(\mathrm{i} \oplus \mathrm{j})$. Here, $\uparrow(\mathrm{i} \oplus \mathrm{j})$ is a group atom to which the property of having swum 2 kilometers applies as a single element (collectively); i swam the first kilometer and then $\mathrm{j}$ swam the second (as in a relay race). For this model, 
$2 \mathrm{~km}$ oyoida 'swam 2 kilometers' denotes a set containing these six atoms and all the sums generated by them. ${ }^{23}$ Now, suppose that $\mathrm{d}, \mathrm{e}, \mathrm{f}, \mathrm{i}$, and $\mathrm{j}$ are students, $\mathrm{g}$ is a professor, and $\mathrm{h}$ is a baboon. Then the classifier nin denotes $\{\mathrm{d}, \mathrm{e}, \mathrm{f}, \mathrm{g}, \mathrm{i}, \mathrm{j}\}$, and the intersection of this set with the set denoted by $2 \mathrm{~km}$ oyoida contains $\{\mathrm{d}, \mathrm{e}, \mathrm{f}, \mathrm{g}\}$, excluding $\mathrm{h}, \uparrow(\mathrm{i} \oplus \mathrm{j})$ and all the sums. For (32a) to be true, there must be a subset $\mathrm{K}$ of $\{\mathrm{d}, \mathrm{e}, \mathrm{f}, \mathrm{g}\}$ that has a cardinality of 3 . Furthermore, the supremum of the subset must be part of an element of the student set. Indeed there is such a $\mathrm{K}$, namely $\{\mathrm{d}, \mathrm{e}, \mathrm{f}\}$. Hence sentence (32a) is true of this model. ${ }^{24}$

Note how a distributive reading necessarily obtains here. In FNQ quantification the classifier denotation and the predicate denotation intersect. Due to the atomicity constraint on the classifier denotation, only atoms are in this intersection. Thus, the predicate applies to these atoms individually, hence the distributivity. A collective predicate (e.g. gasshooshita 'sang in chorus') denotes a set containing only group atoms and their sums. In this case, if an individual-kind classifier (e.g. nin 'person') were used, its atomicity constraint would exclude everything from its intersection with the predicate denotation, making this intersection the null set. There would be no cardinality set $\mathrm{K}$, therefore the sentence would be semantically ill-formed (always false). This is why a collective predicate is generally incompatible with an FNQ. The classifier must be a group-kind (e.g. kumi 'group', soku 'pair') to begin with for an FNQ sentence with a collective predicate to be felicitous (e.g. gakusei-ga, sankumi gasshooshita 'Three groups of students each sang in chorus').

Let us elaborate a bit more on the group-kind classifier kumi 'group'. Kumi is a unit for counting groups, where the type of group and the number of members are irrelevant. ${ }^{25}$ It has a meaning similar to that of the English word group in constructions like three groups of boys (also three flocks of geese, three fleets of trawlers); however, like the English word committee, the 'groups' referred to by kumi may consist of a single member. The set denoted by the

\footnotetext{
${ }^{23}$ Following Landman (2000), I assume that a plural predicate denotation can automatically be derived from a singular predicate denotation by including all sums formed by the sums.

${ }^{24}$ The definition of the semantic value of the numeral in (32b) leaves open the possibility of an 'at least' reading of the numeral. If choodo 'exactly' were added to (32a), its meaning would change as follows:

(i) gakusei-ga choodo san-nin $2 \mathrm{~km}$ oyoida. 'Exactly three students swam $2 \mathrm{~km}$.'

$$
\begin{aligned}
& \exists \mathrm{y}\left[\operatorname{GAKUSEI}(\mathrm{y}) \wedge \exists \mathrm{K}\left[\mathrm{K} \subseteq\left(\mathrm{NIN}_{\mathrm{AT}} \cap 2 \mathrm{KM} \text { OYOIDA }\right) \wedge|\mathrm{K}|=3 \wedge \oplus \mathrm{K} \Pi \mathrm{y}\right]\right] \wedge \\
& \text { student nin } 2 \mathrm{~km} \text { swam } \\
& \neg \exists \mathrm{y}\left[\operatorname { G A K U S E I } ( \mathrm { y } ) \wedge \exists \mathrm { K } \left[\mathrm{K} \subseteq\left(\mathrm{NIN}_{\mathrm{AT}} \cap 2 \mathrm{KM} \text { OYOIDA }\right) \wedge|\mathrm{K}|>3 \wedge \oplus \mathrm{K}\right.\right. \text { Пy]] }
\end{aligned}
$$$$
\text { student nin } 2 \mathrm{~km} \text { swam }
$$

Note that Japanese choodo syntactically combines with the NQ, rather than with the Num alone (both choodo 10-nin-no kodomo 'exactly 10 children' and 10-nin choodo-no kodomo 'exactly 10 children' are grammatical). For native English speakers this may seem unintuitive since English numerals appear to be simplex, i.e. to be Num rather than [Num-CL], and seem to be directly modified by exactly. However, the English numeral could actually be an NQ with a hidden classifier (see Sect. 8). Moreover, note that English exactly can modify elements of different syntactic categories (e.g. exactly 3 boys, exactly the same people, etc.). I will leave this matter for future research.

${ }^{25}$ Some other examples of this type of classifier are -soku for counting pairs of footwear (socks and shoes), -zen for counting pairs of chopsticks, -taba for counting bundles, and -yama for counting piles. 
classifier -kumi contains singular 'kumi-individuals', i.e. group atoms. When this set intersects with the predicate denotation, the intersection contains singular kumi-individuals that have the property specified by the predicate. For example, imagine an audition for a music festival in which three singers and six bands made entries. In this situation the following sentence is true:

$\begin{array}{lllll}\text { wakamonotachi-ga } & \begin{array}{l}\text { kono } \\ \text { oodishon-ni, }\end{array} & \text { 9-kumi } & \text { sankashita. } \\ \text { youth-NOM } & \text { this } & \text { audition-in } & 9-C L & \text { participated }\end{array}$
'Nine groups of young people participated in this audition.'

Here, each of the three singers counts as a group entity just as much as each of the six bands, and each of the six bands counts as a singular participant just as much as each of the three individual singers. This is a distributive reading because (33) asserts that nine kumi-individuals each had the property of participating in the audition. The property in question is distributed over individual groups even though the activities of the members of some of these groups are collective. ((33) does not describe those collective activities.)

Note that a predicate with a delimiting expression such as $2 \mathrm{~km}$ oyoida 'swam 2 kilometers' excludes a cover reading. For example, in the situation we considered earlier, five students $\mathrm{d}, \mathrm{e}, \mathrm{f}, \mathrm{i}$, and $\mathrm{j}$ swam; however, $\mathrm{i}$ and $\mathrm{j}$ in the group atom $(\uparrow(\mathrm{i} \oplus \mathrm{j}))$ cannot be decomposed since the property of swimming 2 kilometers does not apply to each of these individuals. For this reason, the following discourse fragment is incoherent: ${ }^{26}$

(34)a. gakusei-ga, go-nin $2 \mathrm{~km}$ oyoida.

student-NOM 5-CL $2 \mathrm{~km}$ swam

'Five students swam 2 kilometers.'

b. sonouchi futa-ri-wa $1 \mathrm{~km}$-zutsu oyoida.

that within 2-CL-TOP 1 km-each swam

'Among them, two swam 1 kilometer each.'

Let us now turn to the case of an object-oriented FNQ. Consider the FNQ sentence in $(35):{ }^{27}$

\footnotetext{
${ }^{26}$ However, with many predicates a cover reading can be acceptable, if there is no overt delimiting expression like 'two kilometers'. I speculate that a loose interpretation of the predicate is responsible for this. A similar phenomenon is observed in (i):
}

(i) The boys all built the raft.

The general consensus is that a sentence with FQ all strongly prefers a distributive reading. Nonetheless, (i) can be acceptable as a "true enough" description of a situation in which all of the boys worked together to build a single raft. I suspect that what is going on in such cases is that the predicate is being reanalyzed as something like 'participated in a raft-building activity'. In other words, lexically ill-formed meanings are sometimes taken as acceptable in ordinary language use.

${ }^{27}$ As for the denotation of the predicate, I assume (i) and (ii) below. The latter is derived by typeshifting e to $<<e, t>, t>$ (Partee 1987).

(i) Intransitive verb phrase for a subject-oriented FNQ, e.g. kaetta 'left': $\lambda \mathrm{x}_{\mathrm{e}}[\operatorname{KAETTA}(\mathrm{x})]$

(ii) Transitive verb phrase for an object-oriented FNQ, e.g. katta 'bought': $\lambda \mathrm{T}_{<\mathrm{e}, \mathrm{t}}>\lambda \mathrm{x}_{\mathrm{e}}\left[\mathrm{T}\left(\lambda \mathrm{y}_{\mathrm{e}}[\operatorname{KATTA}(\mathrm{y})(\mathrm{x})]\right)\right]$ 


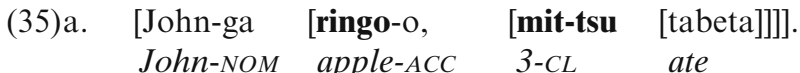

'John ate three apples.'

b. Lexical Entries:

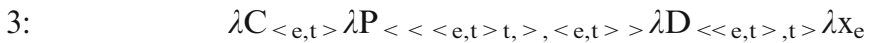

$\mathrm{D}\left[\lambda \mathrm{y}_{\mathrm{e}}\left[\exists \mathrm{K}\left[\mathrm{K} \subseteq\left(\mathrm{C} \cap \lambda \mathrm{z}_{\mathrm{e}}[\mathrm{P}(\lambda \mathrm{N}[\mathrm{N}(\mathrm{z})])(\mathrm{x})]\right) \wedge|\mathrm{K}|=3 \wedge \oplus \mathrm{K} \Pi \mathrm{y}\right]\right]\right]$

tsu 'tsu (CL)': $\lambda \mathrm{u}_{\mathrm{e}}\left[\mathrm{TSU}_{\mathrm{AT}}(\mathrm{u})\right]$

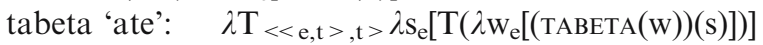

ringo 'apple': $\lambda \mathrm{x}_{\mathrm{e}}[\mathrm{RINGO}(\mathrm{x})]$

$\varnothing$ 'a': $\quad \lambda \mathrm{X}_{<\mathrm{e}, \mathrm{t}>} \lambda \mathrm{Y}_{<\mathrm{e}, \mathrm{t}>} \exists \mathrm{y}[\mathrm{X}(\mathrm{y}) \wedge \mathrm{Y}(\mathrm{y})]$

John: $\quad \lambda \mathrm{S}_{<\mathrm{e}, \mathrm{t}>}[\mathrm{S}(\mathrm{j})]$

Outcome:

$\exists \mathrm{y}\left[\operatorname{RINGO}(\mathrm{y}) \wedge \exists \mathrm{K}\left[\mathrm{K} \subseteq\left(\operatorname{TSU}_{\mathrm{AT}} \cap \lambda \mathrm{z}[(\operatorname{TABETA}(\mathrm{z}))(\mathrm{j})]\right) \wedge|\mathrm{K}|=3 \wedge \oplus \mathrm{K} \Pi \mathrm{y}\right]\right]$ apple tsu ate

The final line of (35b) asserts that there is a set $\mathrm{K}$ which is a subset of the set of atomic $t s u$-objects that John ate, which has a cardinality of three and which consists of apples. ${ }^{28}$ Here again, a distributive reading obligatorily results. The predicate denotation, a set of things that John ate, contains both atoms and sums. However, intersection with the classifier denotation selects only singular atoms, hence the distributive reading. Since the noun ringo 'apple' denotes a set containing both sums and atoms, the supremum generated by $\mathrm{K}$ can be identified as an element in it, a sum. ${ }^{29-31}$

\footnotetext{
${ }^{28}$ The classifier $t s u$ denotes small round objects, among other things.

${ }^{29}$ I differentiate the semantic type of the numeral in subject-oriented and object-oriented FNQs because the predicates they combine with have different logical types. Lexically, the FNQ is specified to have both types and whichever fits the context is used. This is analogous to the systematic type-ambiguity of verbs like eat, which have one logical type for intransitive sentences and another for transitive sentences. If both logical types of the FNQ fit the context, the sentence is ambiguous between a subject- and an object-oriented reading, as exemplified in (i):
}

(i)

$$
\begin{array}{llll}
\text { sensei-ga, } & \text { san-nin } & \text { gakusei-o mita. } \\
\text { teacher-NOM } & 3-C L & \text { student-ACC } & \text { saw }
\end{array}
$$

'Three teachers saw a student.' or 'A teacher saw three students.'

${ }^{30}$ The analysis allows the following entailment relationship without any additional assumptions:

(i) a.

\begin{tabular}{|c|c|c|}
\hline $\begin{array}{lll}\text { gakusei-ga, } & \text { san-nin } & \text { kita. } \\
\text { student-NOM } 3-C L & \text { came }\end{array}$ & $\rightarrow$ & $\begin{array}{ll}\text { gakusei-ga } & \text { kita. } \\
\text { student-NOM } & \text { came }\end{array}$ \\
\hline 'Three students came.' & & 'A/some student(s) came.' \\
\hline $\begin{array}{c}\text { John-ga ringo-o, mit-tsu } \\
\text { John-NOM apple- } A C C \quad 3-C L \\
\text { 'John ate three apples.' }\end{array}$ & $\begin{array}{l}\text { tabeta. } \rightarrow \\
\text { ate }\end{array}$ & $\begin{array}{l}\text { John-ga ringo-o tabeta. } \\
\text { John-NOM apple-ACC ate } \\
\text { 'John ate an/some apple(s).' }\end{array}$ \\
\hline
\end{tabular}

(ii)a.

${ }^{31}$ The analysis outputs the interpretation in (ii) for the sentence (30), in which a DNQ and an FNQ co-occur, provided that the subject DP is understood as definite as shown in (i):

(i) narande hashitteita suu-dai-no torakku 'the several trucks which were running in tandem'

(ii) $\exists \mathrm{K}\left[\mathrm{K} \subseteq\left(\right.\right.$ DAI $_{\text {AT }} \cap H I T$ THE GUARDRAIL $) \wedge|\mathrm{K}|=3 \wedge \oplus \mathrm{K}$ ПTHE SEVERAL TRUCKS WHICH WERE RUNNING IN TANDEM]]

The logical representation in (ii) correctly predicts the partitive reading of (30). 
Finally, let us consider sentences like (36) in which the host NP of the FNQ is a non-argument:

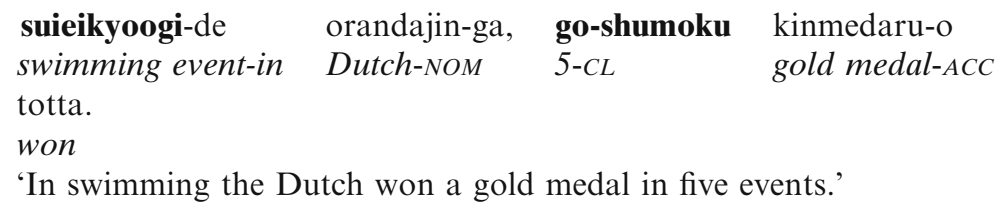

Such sentences are extremely problematic for an account of the Japanese FNQ which takes the host NP to be the domain of quantification. They call for special treatment under my proposal as well; however, no modification to the analysis of numeral quantification is required. Rather, what needs to be modified is the analysis of how the semantic arguments of the predicate in (36) are realized syntactically. A semantic argument is often realized as a syntactic argument, but this is not the case in (36). Here the syntactic adjunct suieikyoogi-de, 'in swimming events' functions as a semantic argument of the complex predicate kinmedaru-o totta 'won gold medals', much as on the table in put the book on the table is semantically an argument though it is syntactically an adjunct (cf. Seiter 1979). In other words, the problem is not specific to (36) but arises just as much in the same sentence without FNQ.

\subsection{The event classifier}

Consider again the pistol sentence:

$$
\begin{aligned}
& \text { pisutoru-ga, san-patsu utareta. } \\
& \text { pistol-NOM } 3-C L \quad \text { were-shot } \\
& \text { (lit.) 'A pistol was shot of three shots.' }
\end{aligned}
$$

The semantic analysis in the last section alluded only to FNQs with a classifier such as nin (people) that denotes objects. To see how this analysis also covers FNQs with event classifiers, recall from the discussion in Sect. 5.1 that an event classifier is of type $<\mathrm{s}, \mathrm{t}>$ and has the following kind of denotation: ${ }^{32}$

$$
\text { hatsu: } \lambda \mathrm{e}_{\mathrm{S}}\left[\operatorname{HATSU}_{\mathrm{AT}}(\mathrm{e})\right] \quad \text { (a set of atomic events of the hatsu-category) }
$$

As we enrich our model to include both event individuals and object individuals, and respective semilattices of both sorts of entity as well, an event classifier can also be considered to be lexically specified as a singular term. ${ }^{33}$ Thus, hatsu denotes a set of atomic hatsu-events (shots/blasts/explosions). Assuming that the numeral can also quantify over events (e.g. three shots), and assuming the atomicity condition, the event classifier san-patsu ' 3 -CL' refers

\footnotetext{
32 The type $s$ is used for event or situation here.

${ }^{33}$ Just like objects, events of a given type can form a join-semilattice consisting of both atoms and sums (Krifka 1989). For example, an event of John shooting a pistol twice can be analyzed as a sum of two atomic events of John shooting a pistol once. I use the term 'event' here in the sense that also includes events without agentive participants (cf. 'situations', 'eventualities').
} 
to three atomic shot/blast/explosion events. In FNQ quantification, then, the set of (atomic) events denoted by the event classifier intersects with the set denoted by the predicate. This means that the predicate denotation must include event individuals as well, since otherwise the two sets could not possibly intersect. Now, quite independently of our analysis of the event classifier, it is generally assumed that all predicates also lexically contain an event or situation variable (Davidson 1967; Higginbotham 1985; Parsons 1990; and many others). On this assumption, an intransitive verb phrase is more precisely analyzed to be of type $<\mathrm{e},<\mathrm{s}, \mathrm{t}>>$, rather than $<\mathrm{e}, \mathrm{t}>$. Thus, the intransitive verb phrase utareta 'was shot' is of type $<\mathrm{e},<\mathrm{s}, \mathrm{t}>>$, as shown in (39).

$$
\begin{array}{ll}
\text { utareta: } \left.\lambda \mathrm{x}_{\mathrm{e}} \lambda \mathrm{e}_{\mathrm{s}} \quad \text { [utAreta }(\mathrm{x})(\mathrm{e})\right] \\
\\
\text { was shot }
\end{array}
$$

The variable $x$ of type e receives its value when the complex predicate composes with the subject pisutoru 'pistol'.

Putting everything together, the semantic analysis of a pistol sentence would be as shown in (40). Here I assume, for the sake of concreteness, that Tense introduces an existential quantifier which binds the event variable. Abstracting away from this, the sentence is of type $<\mathrm{s}, \mathrm{t}>$. Also, maintaining the type of the DP as $<<e, t>, t>$, the type of the intransitive predicate is represented here as $<<<\mathrm{e}, \mathrm{t}>, \mathrm{t}\rangle,<\mathrm{s}, \mathrm{t}>>$, rather than $<\mathrm{e},<\mathrm{s}, \mathrm{t}>>{ }^{34}$ The denotation of the numeral is compelled to accommodate the type of semantic entities which it composes with, though the basic relation between elements remains the same as before.

$\begin{array}{lll}\text { (40)a. pisutoru-ga, } & \text { san-patsu } & \text { utareta. } \\ \text { pistol-NOM } & 3-C L & \text { were shot }\end{array}$

'Three shots of a pistol were shot.'

b. Lexical Entries:

hatsu 'hatsu (CL)': $\lambda \mathrm{e}_{\mathrm{S}}\left[\operatorname{HATSU}_{\mathrm{AT}}(\mathrm{e})\right]={ }_{\mathrm{abbr}}$. $\mathrm{HATSU}_{\mathrm{AT}}$

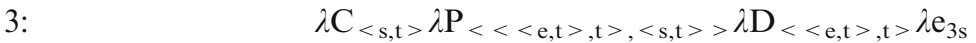
$\exists \mathrm{K}\left[\mathrm{K} \subseteq(\mathrm{C} \cap \mathrm{P}(\mathrm{D})) \wedge|\mathrm{K}|=3 \wedge \oplus \mathrm{K} \mathrm{e}_{3}\right]$

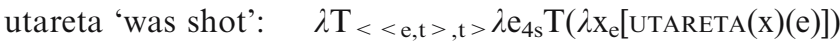

pisutoru 'pistol': $\quad \lambda \mathrm{x}_{\mathrm{e}}$ [PISUTORU(x)]

$\varnothing$ 'a': $\quad \lambda \mathrm{X} \lambda \mathrm{Y} \exists \mathrm{y}[\mathrm{X}(\mathrm{y}) \wedge \mathrm{Y}(\mathrm{y})]$

Outcome:

$\lambda \mathrm{e}_{3} \exists \mathrm{K}\left[\mathrm{K} \subseteq\left(\operatorname{HATSU}_{\mathrm{AT}} \cap \lambda \mathrm{e}_{4} \exists \mathrm{y}\left[\operatorname{PiSUTORU}(\mathrm{y}) \wedge \operatorname{UTARETA}(\mathrm{y})\left(\mathrm{e}_{4}\right)\right]\right) \wedge|\mathrm{K}|=3 \wedge \oplus \mathrm{K} \mathrm{e}_{3}\right]$ hatsu pistol was shot

\footnotetext{
${ }^{34}$ In an attempt to achieve type-logical uniformity, one could alternatively assume that the type of the intransitive verb phrase under object quantification was $<<<e, t>, t>, t>$, or even $<<<e, t>, t>,<\mathrm{s}, \mathrm{t}>>$, rather than $<\mathrm{e}, \mathrm{t}>$. However, our main concern is the semantic value of the formulas rather than type-logical uniformity. Thus, I will not bother to revise the previous formulation of object quantification.
} 
The final line of the derivation asserts (i) that there is a set of events $\mathrm{K}$ which is a subset of the intersection of the set of atomic hatsu-events (shots/explosions) and the set of pistol shooting events, (ii) that the number of these events is three, and (iii) that the supremum of these atomic events is part of the eventuality the speaker reports. In short, the final interpretation is that there occurred an event which consisted of three explosions having to do with a pistol. This is exactly the proposition asserted by the sentence in (40a).

Note that, since quantification is computed on the basis of events, in (40a) the denotation of the NP pisutoru 'pistol' is related to the cardinality set of events K only insofar as it is a participant in these events. Quantification here has nothing to do with the quantity of pistols taken as objects. As evidence of this, note that adding an overt demonstrative such as korerano 'these' to pisutoru 'pistol' in (40a) does not force a partitive reading; Korerano pisutoruga san-patsu utareta means 'Three shots were shot with these pistol(s)'. In contrast, when an object classifier such as nin is used, which quantifies over object individuals, adding a demonstrative forces the FNQ to have a partitive reading, analogous to (30).

\section{DNQ quantification}

Just as the semantic analysis of the FNQ was closely tied to its syntax, the analysis of the DNQ will be closely tied to the syntactic analysis in Sect. 3 .

\subsection{Interpretation of the DNQ sentence}

Given the constituent structure of the DNQ sentence, discussed in Sect. 3, I propose that function composition of DNQ sentence interpretation occurs in the following order: (i) $\mathrm{Num}+\mathrm{CL} \rightarrow \mathrm{NQ}$, (ii) $\mathrm{NQ}+\mathrm{NP} \rightarrow \mathrm{NP}$, (iii) $\mathrm{Det}+\mathrm{NP} \rightarrow \mathrm{DP}$, and finally (iv) $\mathrm{DP}+\mathrm{VP} \rightarrow \mathrm{S} .{ }^{35}$ Consider the example in (41):

\footnotetext{
${ }^{35}$ Some syntacticians have suggested that the classifier first composes with the host NP, forming a $[\mathrm{CL}+\mathrm{N}]$ constituent, and that this constituent then composes with the numeral, yielding a constituent of the form [Num $[\mathrm{CL}+\mathrm{N}]$, as illustrated in (i) and (ii):

(i)

[san [zhi bi]]

3 CL pen

Chinese (e.g. Cheng and Sybesma 1999, see also Yang 2001)

'three pens'

(ii) [three [bottles of wine]]

English (Corver 1998)
}

However, that the constituency structure in Japanese must be $[[\mathrm{Num}+\mathrm{Cl}]+\mathrm{NP}]$ and not $[\mathrm{Num}+[\mathrm{Cl}+\mathrm{NP}]]$ is clear from the following four separate observations; (i) the word-internal voicing rule called rendaku can occur with a Japanese NQ (e.g. /san/ '3' + /hon/ 'CL' $\rightarrow$ /san-bon/), (ii) a Japanese NQ can undergo the word-internal morphological process of suppletion (e.g. ichinin $\rightarrow$ hitori); (iii) the NP can occur left adjacent to a Japanese NQ (e.g. enpitsu san-bon 'pencil 3-CL'); and (iv) the FNQ composes with the predicate, not the host NP, as discussed in Sect. 3. 
(41)a. [[san-nin-no [gakusei]]-ga $[2 \mathrm{~km}$ oyoida $]$. 3-CL-GEN student-NOM $2 \mathrm{~km}$ swam 'Three students swam $2 \mathrm{~km}$.'

b. Lexical Entries: same as in (32b)

Outcome:

$$
\begin{array}{cc}
\exists \mathrm{y}\left[\exists \mathrm{K}\left[\mathrm{K} \subseteq\left(\mathrm{NIN}_{\mathrm{AT}} \cap \text { GAKUSEI }\right) \wedge|\mathrm{K}|=3 \wedge \oplus \mathrm{K} \prod \mathrm{y}\right] \wedge 2 \mathrm{KM} \text { OYOIDA }(\mathrm{y})\right] \\
\operatorname{nin} \text { student } & \operatorname{swam~} 2 \mathrm{~km}
\end{array}
$$

The result of the semantic computation is the proposition (i) that there is a set $\mathrm{K}$ which is a subset of the intersection of the set of atomic nin-objects and the set of students, (ii) that the number of the elements in $\mathrm{K}$ is three, and (iii) that the supremum generated by $\mathrm{K}$ is part of an element of the set denoted by $2 \mathrm{~km}$ oyoida 'swam $2 \mathrm{~km}$ '.

This interpretation differs from that of the FNQ sentence only in that the host NP and the predicate denotation have swapped function (compare with (39)). In the case of a DNQ, the classifier denotation intersects with the host NP denotation instead of the predicate denotation, and the sum generated by $\mathrm{K}$ is found in the predicate denotation instead of the host NP denotation. The set denoted by the host NP gakusei 'student' contains atoms and sums, and due to the atomicity constraint of the classifier, the intersection of the classifier denotation and the host NP denotation contains only atoms, namely persons who are students. The set $\mathrm{K}$ has three elements. If we represent them as $\mathrm{a}, \mathrm{b}$, and $\mathrm{c}$, then the supremum, namely $\mathrm{a} \oplus \mathrm{b} \oplus \mathrm{c}$, is asserted to be part of an element denoted by $2 \mathrm{~km}$ oyoida 'swam 2km'. Informally, (41a) asserts that there are three students who swam $2 \mathrm{~km}$. As the reader can readily verify, object-oriented DNQ sentences are covered by the same analysis.

\subsection{On the ambiguity of DNQs}

As noted in Sect. 2, DNQ sentences are in principle ambiguous, allowing a distributive, collective, or cover reading. Complete ambiguity arises when the predicate is of the mixed type. ${ }^{36}$ For example, the sentence in (42) is true of any of the situation types represented in (43).

$$
\begin{aligned}
& \text { san-nin-no gakusei-ga peepaa-o kaita. } \\
& \text { 3-CL-GEN student-NOM paper-ACC wrote } \\
& \text { 'Three students wrote a paper.' }
\end{aligned}
$$

\footnotetext{
${ }^{36}$ Lexically distributive predicates and lexically collective predicates (Bennett 1974) force the interpretation of the sentence to be distributive or collective, respectively:

(i) 'Three students walked.' (distributive predicate $\rightarrow$ \#collective reading)

(ii) 'Three students formed a single circle.' (collective predicate $\rightarrow$ \#distributive reading)
} 
(43)a. Distributive

$\mathrm{a}=$ paper writer

$\mathrm{b}=$ paper writer

$\mathrm{c}=$ paper writer b. Cover

$(\mathrm{a} \oplus \mathrm{b})_{\text {group }}=$ paper writer

$\mathrm{b}=$ paper writer

$\mathrm{c}=$ paper writer

c. Collective

$(\mathrm{a} \oplus \mathrm{b} \oplus \mathrm{c})_{\text {group }}=$ paper writer

The question is why this ambiguity arises with DNQs but not with FNQs. According to the proposed analysis, the meaning of the DNQ sentence (42) is (44).

$$
\begin{aligned}
& \exists \mathrm{y}\left[\exists \mathrm{K}\left[\mathrm{K} \subseteq\left(\mathrm{NIN}_{\mathrm{AT}} \cap \mathrm{GAKUSEI}\right) \wedge|\mathrm{K}|=3 \wedge \oplus \mathrm{K} \Pi \mathrm{y}\right] \wedge \operatorname{PEEPAA-O} \operatorname{KAITA}(\mathrm{y})\right] \\
& \text { nin student wrote a paper }
\end{aligned}
$$

The core of this logical representation is the last conjunct, which asserts that a three-student sum is an element of the paper-writer set. Letting $\mathrm{K}$ be the sum $\mathrm{a} \oplus \mathrm{b} \oplus \mathrm{c}$, this can be stated as follows:

\section{$\mathrm{a} \oplus \mathrm{b} \oplus \mathrm{c} \in$ PEEPAA-O KAITA}

In fact, the ambiguity here is an instance of a very general phenomenon. A sum of individuals, such as $\mathrm{a} \oplus \mathrm{b} \oplus \mathrm{c}$, is what is referred to by a plural term, and a plural term is generally ambiguous as regards distributive, collective, or cover readings (Gillon 1987):

(44)a. John, Bill and Tom wrote a paper.

(D/C/Cov)

b. Three students wrote a paper.

(D/C/Cov)

c. These students wrote a paper.

$(\mathrm{D} / \mathrm{C} / \mathrm{Cov})$

d. They wrote a paper.

(D/C/Cov)

Furthermore, this phenomenon is not specific to English. Exactly the same thing can be said for Japanese:

(45)a. Ken-to Daisuke-to Mari-ga ronbun-o kaita. (D/C/Cov) Ken-and Daisuke-and Mari-NOM paper-ACC wrote 'Ken, Daisuke, and Mari wrote a paper.'
b.
gakusei-ga
ronbun-o
kaita.
(D/C/Cov)

3-CL-GEN

student-NOM

paper- $A C C$

wrote

'Three students wrote a paper.'

$\begin{array}{llll}\text { c. kono hito-tachi-ga } & \text { ronbun-o kaita. } & \text { (D/C/Cov) } \\ \text { this person-etc. }- \text { oM paper-ACC } & \text { wrote } & \\ \text { 'These people wrote a paper.' } & & \\ \text { d. karera-ga ronbun-o kaita. } & & \text { (D/C/Cov) } \\ \text { they-NOM paper-ACC wrote } & & \\ \text { 'They wrote a paper.' } & & \end{array}$


Thus, the interpretational ambiguity of the plural term seems to be general enough. Why this is the case is a separate issue, and exactly how this ambiguity should formally be captured is also beyond the scope of this paper. The reader is referred to the relevant literature; e.g. Link (1984), Chierchia (1998a), Landman (2000). For a specific account of the ambiguity of the Japanese DNQ cast in the framework of Landman (2000), see Kobuchi-Philip (2003b, 2006). ${ }^{37}$

It must be emphasized, however, that the analysis put forth in this paper clearly distinguishes DNQ quantification from FNQ quantification precisely as regards the ambiguity in question. DNQ quantification outputs a plural term, thus its ambiguity is predicted as an instance of a general phenomenon. In contrast, in FNQ quantification there is no plural term, so there is no ambiguity. The classifier denotation intersects with a predicate denotation, not with a noun denotation.

\section{Agreement}

In this section, I return to our question concerning the classifier-host NP agreement phenomenon, illustrated again in the DNQ sentences in (46) and the FNQ sentences in (47). Here the classifier meanings are given a more literal gloss, reflecting the claims of the proposed analysis.

(46)a. san-nin-no gakusei-ga kita.

3-CL-GEN student-NOM came

'Three person-objects of students came.'

b. \#san-biki-no gakusei-ga kita

3-CL-GEN student-NOM came

'Three small animal-objects of students came.'

(47)a. gakusei-ga, san-nin kita.

student-NOM 3-CL came

'Three person-objects of students came.'

b. \#gakusei-ga, san-biki kita.

student-NOM 3-CL came

'Three small animal-objects of students came.'

The contrasts observed in the minimal pairs in (46) and (47) can be compared with those seen in the English minimal pairs in (48) and (49).

(48)a. A handful of students disobeyed the teacher.

b. \#A herd of students disobeyed the teacher.

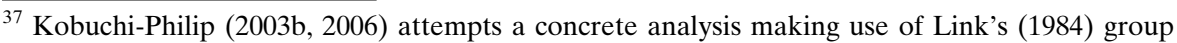
operator. According to the analysis, a collective reading is derived from a default distributive reading via an application of a group operator to the sum $\mathrm{K}$. Likewise, a cover reading is derived via a different reanalysis operation, also to the sum $\mathrm{K}$.
} 
(49)a. A branch suddenly hit the car.

b. \#A branch deliberately hit the car.

The same principle that accounts for the English anomalies in (48b) and (49b) can also be seen to account for the Japanese agreement anomalies in (46b) and (47b). It is simply a matter of selectional restriction violations. A sentence interpretation is computed by function composition in a bottom-up fashion. Consequently, a semantically well-formed sentence must preserve coherent meaning at all points of composition. Consider now the following schema, which shows a step-by-step function composition. (50a) is an English sentence which includes a DP-internal modifier and (50b) is a Japanese DNQ sentence:

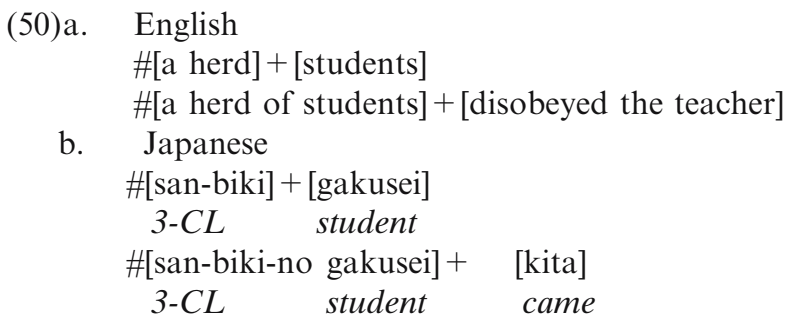

In (50a), a herd and students must first be composed. However, since there is no entity which has the property of being a herd and the property of being students at the same time, the intersection of the two denotations is the null set. Already at this point, the composition cannot preserve coherent meaning, and thus the whole sentence is ill-formed. The ill-formedness of the DNQ sentence (50b) can be explained in exactly the same fashion. ${ }^{38}$ Next, consider (51). (51a) is an English sentence with an adverb and (51b) is a Japanese FNQ sentence:

(51)a. English

[deliberately] $+[$ hit the car]

$\#[$ a branch $]+$ [deliberately hit the car]

b. Japanese

[san-biki] $+[$ kita]

3-CL came

\#[gakusei] + [san-biki kita]

student 3-CL came

\footnotetext{
${ }^{38}$ A DNQ with an event classifier can generally only compose with an event-denoting nominal, as shown below:

(i) [san-patsu-no shageki] vs.

3-CL SHOT $^{-G E N}$ shot

'three bursts of shots'
\#[san-patsu-no pisutoru]
3-CL $L_{s c}>$ shot ${ }^{-G E N}$ pistol
\#'three bursts of pistols'

(ii) [san-kai-no kazan-funka ] vs. \#[san-kai-no funka-kazan]

3-CL $L_{T I M E}-G E N$ volcano eruption 3-CL $3 C>$ time-GEN eruption volcano

'three times of volcano eruption' \#'three times of erupting volcano'
} 
In (51a), the composition of deliberately and hit the car preserves coherent meaning, since a car could be deliberately hit by some agent. However, semantic ill-formedness occurs at the next point of composition. A branch denotes a set of objects that cannot be agents, but deliberately hit the car denotes a set of agents. Consequently, the intersection of these two sets is, once again, the null set. The ill-formedness of the FNQ sentence in (51b) can be explained in exactly the same fashion. Gakusei 'student' denotes a set of people; san-biki kita denotes a set of animals (i.e. not people) that arrived. The intersection of these two sets is again null and accommodation must take over for any sense to be made of the sentence. In sum, the agreement of the classifier and the host NP can be explained semantically in terms of selectional restriction. In support of this analysis, note that just as selectional restrictions can be deliberately violated by English native speakers in their actual use of language, so too can Japanese native speakers deliberately produce agreement violations for some special effect. For example, (47b) could be uttered as a joke. This itself argues against analyzing Japanese classifier-NP agreement as syntactic agreement (cf. Kitahara 1992). Syntactic agreement is virtually never deliberately violated (unless one is pretending not to be a native speaker). For example, it is hard to see how one could make a joke out of a statement such as *John are leaving; it simply shows an ignorance of English grammar. Semantic agreement, on the other hand, can be, and frequently is, deliberately violated in special uses of language (hyperbole, poetry, jokes, etc.).

\section{Summary and implications}

The starting point of this paper was the empirical observation that the Japanese FNQ sentence generally has a distributive reading. This basic fact has been captured by the atomicity of the classifier in composition with the predicate, given the analysis in (52):

Japanese Numeral Quantification

\begin{tabular}{|l|l|l|l|}
\hline & Quantifier & $1^{\text {st }}$ Argument & $2^{\text {nd }}$ Argument \\
\hline DNQ & Numeral & Classifier & NP \\
\hline FNQ & Numeral & Classifier & Predicate \\
\hline
\end{tabular}

The fact that the DNQ sentence is ambiguous, alternatively allowing a collective or cover reading, was accounted for in terms of semantic operations that apply to plural terms in general. Aside from achieving this, the proposed analysis has the following advantages: (i) it offers a unified account of DNQ and FNQ quantification in Japanese; (ii) it derives the semantic difference between DNQ and FNQ quantification directly from their syntactic difference; (iii) it also captures FNQ quantification with object classifiers such as nin and event classifiers such as hatsu; (iv) it explains the agreement between the classifier inside an NQ and a host NP in the simplest possible terms. 
If on the right track, the proposed analysis of the Japanese FNQ has implications for several linguistic issues. I would like to briefly discuss two of them. One concerns the semantics of numeral quantification in general, and the other concerns the semantics of floating quantifiers in general. According to our analysis, a numeral is not a determiner of type $\langle<e, t>,<<e, t>, t>>$. This suggests that the standard analysis (e.g. Barwise and Cooper 1981), in which a numeral is taken to be a determiner, should perhaps be reconsidered. ${ }^{39}$ In English, a count noun such as boy can be modified by a numeral alone, without a classifier. However, note that English also has a number of classifiers, which occur with numerals in pseudopartitive constructions, e.g. two flocks of birds, two sheets of paper, etc. While it is possible to hypothesize that there are two different semantic mechanisms underlying these two types of numeral modification, clearly it would be preferable to have a unified analysis. From this perspective, the simplest hypothesis would be that classifiers are present in all forms of numeral quantification. According to the hypothesis put forth in this paper, a classifier or something equivalent to it is necessary to ensure the atomicity condition of the domain of quantification. Given that a plural term such as boys denotes a set containing sums, as is generally assumed in the literature, and that the numeral in the phrase two boys seems to lack a domain of quantification, it can plausibly be suggested that English actually has a phonetically null classifier element. If such a hypothesis can be maintained, it will bring us a step closer to a principled analysis of classifier and non-classifier NPs in English, and also a step closer to a principled analysis of classifier and non-classifier languages (see Kobuchi-Philip 2006, for concrete discussion).

Another issue for which the current hypothesis has an implication is the semantics of floating quantifiers (FQs) crosslinguistically. If on the right track, the analysis proposed here suggests that FQs in general are predicate modifiers. In fact, this has been suggested in the semantics literature for ages. However, the proposed analysis of the FNQ suggests something more; it suggests that the FQ lexically contains its domain of quantification and that FQ quantification is computed in the verbal domain. This is rather an attractive hypothesis because it will, in the same fashion as in the case of Japanese FNQs, account for the widely held observation that FQ sentences in languages like English and French yield a distributive reading. Although this hypothesis might seem poorly motivated in the case of English, because English FQs do not contain an audible nominal element corresponding to the classifier in Japanese, some empirical support can be found in several other languages. One piece of evidence is that, not only in Japanese but across classifier languages, if a numeral appears as an FQ, a classifier is regularly associated with it. Consider, for instance, $(53 a, b)$ :

\footnotetext{
39 A number of authors (Verkuyl 1981, and many others) discuss the numeral as a semantic element other than a determiner.
} 
(53)a. mahasiswa tiga-orang (*tiga) menulis paper. (Bahasa Indonesian) student 3-CL write paper

'Three (of the) students wrote a paper.'

b. Cengswu-ka sakwa-lul sey-kay (*sey) mekessta. (Korean)

Cengswu-NOM apple-ACC 3-CL ate

'Cengswu ate three apples.'

As with Japanese, the classifier can be considered a domain of quantification for the numeral. Next, consider French and Spanish. Here the expression that corresponds to English floated each contains the overt lexical component 'one':

(54)a. Les enfants ont chac+un (*chaque) acheté deux bonbons. (French) the children each + one bought two candies

'The children each bought two candies.'

b. Los estudiantes escogieron cada uno (*ada) dos temas. (Spanish) the students picked each one two topics

'The students each picked two topics.

The systematic presence of 'one' is mysterious if there is no semantics behind it. My tentative suggestion is that this element is actually a domain of quantification denoting a set of atoms. Additional evidence is found in Dutch, as much a Germanic language as English. The Dutch FQ allemaal 'all' contains an overt nominal element, namely maal 'time', as shown in (55). Note that alle alone cannot be an FQ:

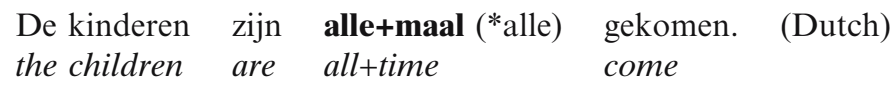

'The children all came.'

Crosslinguistic data such as these support the hypothesis that FQs in general contain their domain of quantification, either as an overt classifier (Japanese, Korean, BI), or as some other overt nominal element (French, Spanish, Dutch), or as a phonetically null nominal element. Of course, if this line of analysis is to be pursued, a number of questions need to be addressed. For instance, what is the relation between an FQ and the same lexical element appearing as a DQ? Why are FQs generally limited to only certain lexical items in many languages? These are old questions but now they can be asked from a new perspective.

\section{References}

Barwise, J., \& Cooper, R. (1981). Generalized quantifiers and natural language. Linguistics and Philosophy, 4, 159-219.

Bennett, M. (1974). Some extensions of a Montague fragment of English. PhD dissertation, UCLA. Brisson, C. (1998). Distributivity, maximality, and floating quantifiers. PhD dissertation, Rutgers University. 
Cheng, L. L.-S., \& Sybesma, R. (1999). Bare and not-so-bare nouns and the structure of NP. Linguistic Inquiry, 30, 509-542.

Chierchia, G. (1998a). Reference to kinds across languages. Natural Language Semantics, 6, 339-405.

Chierchia, G. (1998b). Plurality of mass nouns and the notion of semantic parameter. In S. Rothstein (Ed.), Events and grammar (pp. 53-103). Dordrecht: Kluwer.

Corver, N. (1998). Predicate movement in pseudopartitive constructions. In A. Alexiadou \& C. Wilder (Eds.), Possessors, predicates, and movement in the determiner phrase (pp. 215-257). Amsterdam: John Benjamins.

Davidson, D. (1967). The logical form of action sentences. In N. Rescher (Ed.), The logic of decision and action (pp. 217-232). Pittsburgh: University of Pittsburgh Press.

Den Dikken, M., \& Singhapreecha, P. (2005). Complex noun phrases and linkers. Syntax, 7, 1-54.

Dowty, D., \& Brodie, B. (1984). The semantics of 'floated' quantifiers in a transformationless grammar. In M. Cobler, S. Mackaye, \& M. T. Wescoat (Eds.), Proceedings of the Third west coast conference on formal linguistics (pp. 75-90). Stanford: CSLI.

Fujita, N. (1994). On the nature of modification: A study of floating quantifiers and related constructions. PhD dissertation, University of Rochester.

Fukushima, K. (1991). Generalized floating quantifiers. PhD dissertation, University of Arizona.

Gillon, B. (1987). The readings of plural noun phrases in english. Linguistics and Philosophy, 10, $199-220$.

Gunji, T., \& Hasida, K. (1998). Measurement and quantification. In T. Gunji \& K. Hasida (Eds.), Topics in constraint-based grammar of Japanese (pp. 39-79). Dordrecht: Kluwer.

Hasegawa, N. (1991). On non-argument quantifiers. Metropolitan linguistics, 11, (pp. 52-78). Tokyo: Linguistic Circle of Tokyo Metropolitan University.

Heim, I. (1982). The semantics of definite and indefinite noun phrases. PhD dissertation, University of Massachusetts at Amherst.

Higginbotham, J. (1985). On semantics. Linguistic Inquiry, 16, 547-593.

Hoeksema, J. (1983). Plurality and conjunction. In A. ter Meulen (Ed.), Studies in modeltheoretic semantics (pp. 63-83). Dordrecht: Foris.

Hoeksema, J. (1996). Floating quantifiers, partitives and distributivity. In J. Hoeksema (Ed.), Partitives (pp. 57-106). Berlin: Mouton de Gruyter.

Inoue, K. (1978). Nihongo-no bunpookisoku. Tokyo: Taishuukan.

Ishii, Y. (1998). Floating quantifiers in Japanese: NP quantifiers, VP quantifiers, or both? In Researching and verifying an advanced theory of human language. Report 2, pp. 149-171. Kanda University of International Studies. Also in M. Muraki \& E. Iwamoto (Eds.), 1999, Linguistics: In search of the human mind (pp. 236-267). Tokyo: Kaitakusha.

Junker, M.-O. (1990). Floating quantifiers and Georgian distributivity. In M. Ziolkowski, M. Noske, \& K. Deaton (Eds.), CLS 26 (pp. 211-219). Chicago: Chicago Linguistic Society.

Kamio, A. (1983). Meishiku-no koozoo. In K. Inoue (Ed.), Nihongo-no kihonkoozoo (pp. 77-126). Tokyo: Sanseidoo.

Kang, B.-M. (1994). Plurality and other semantic aspects of common nouns in Korean. Journal of East Asian Linguistics, 3, 1-24.

Kato, S. (1997). Nihongo-no rentaisuuryooshi-to yuurisuuryooshi-no bunseki. Toyama Daigaku Jinmongakubu Kiyoo, 26, 31-64.

Kawashima, R., \& Kitahara, H. (1993). On the distribution and interpretation of subjects and their numeral classifiers. In U. Lahiri \& A. Wyner (Eds.), Semantic and linguistic theory 3 (pp. 97-116). Ithaca: Cornell University.

Kitagawa, Y., \& Kuroda, S.-Y. (1992). Passive in Japanese. Manuscript, University of Rochester and University of California, San Diego.

Kitahara, H. (1992). Numeral classifier phrases inside DP and the Specificity Effect. In S. Choi (Ed.), Japanese and Korean Linguistics 3 (pp. 171-186). Stanford: CSLI Publications.

Kobuchi-Philip, M. (2003a). Syntax of the Japanese postnominal DP-internal numeral quantifier. Talk presented at Taalkunde in Nederland-Dag, Utrecht University.

Kobuchi-Philip, M. (2003b). Distributivity and the Japanese floating numeral quantifier. PhD dissertation, CUNY Graduate Center.

Kobuchi-Philip, M. (2006). Identity of the domain of quantification for numerals. In L. Tasmowski \& S. Vogeleer (Eds.), Non-definiteness and plurality (pp. 267-290). Amsterdam: John Benjamins.

Koike, S. (1999). A monosemy approach to the Japanese particle no: Functional categories as linkers and antisymmetry in natural language. PhD dissertation. CUNY Graduate Center. 
Koizumi, M. (1995). Phrase structure in Minimalist Syntax. PhD dissertation, MIT.

Kratzer, A. (1989). An investigation of the lumps of thought. Linguistics and Philosophy, 12, 607-653.

Krifka, M. (1989). Nominal reference, temporal constitution and quantification in event semantics. In R. Bartsch, J. van Benthem \& P. van Emde Boas (Eds.), Semantics and contextual expression (pp. 75-115). Dordrecht: Foris.

Krifka, M. (1990). Four thousand ships passed through the lock: Object-induced measure functions on events. Linguistics and Philosophy, 13, 487-520.

Kuno, S. (1973). The structure of the Japanese language. Cambridge, Mass.: MIT Press.

Landman, F. (2000). Events and plurality. Dordrecht: Kluwer.

Lasersohn, P. (1988). A semantics for groups and events. PhD dissertation, The Ohio State University.

Lasnik, H., \& Saito, M. (1992). Move $\alpha$. Cambridge, Mass: MIT Press.

Link, G. (1983). The logical analysis of plural and mass terms: A lattice-theoretical approach. In R. Bäuerle, C. Schwarze, \& A. von Stechow (Eds.), Meaning, use, and interpretation of language (pp. 302-323). Berlin: de Gruyter.

Link, G. (1984). Hydras. On the logic of relative clause constructions with multiple heads. In F. Landman \& F. Veltman (Eds.), Varieties of formal semantics (pp. 245-257). Dordrecht: Foris.

Link, G. (1987). Generalized quantifiers and plurals. In P. Gärdenfors (Ed.), Generalized quantifiers. Linguistic and logical approaches (pp. 151-180). Dordrecht: Reidel.

Lønning, J. T. (1987). Mass terms and quantification. Linguistics and Philosophy, 10, 1-52.

Lyons, J. (1977). Semantics. Cambridge: Cambridge University Press.

Nakanishi, K. (2004). Domains of measurement: Formal properties of non-split/split quantifier constructions. PhD dissertation, University of Pennsylvania.

Nakayama, M., Koizumi, M. (1991). Remarks on Japanese subjects. Lingua, 85, 303-319.

Parsons, T. (1970). An analysis of mass terms and amount terms. Foundations of Language, 6, 362-388.

Parsons, T. (1990). Events in the semantics of English. A study in subatomic semantics. Cambridge, Mass.: MIT Press.

Partee, B. (1987). Noun phrase interpretation and type-shifting principles. In J. Groenendijk, D. de Jongh, \& M. Stokhof (Eds.), Studies in discourse representation theory and the theory of generalized quantifiers (pp. 115-143). Dordrecht: Foris.

Roberts, C. (1986). Modal subordination, anaphora and distributivity. PhD Dissertation, University of Massachusetts at Amherst.

Saito, M. (1985). Some asymmetries in Japanese and their theoretical implications. PhD dissertation, MIT.

Sasaki Alam, Y. (1997). Numeral classifiers as adverbs of quantification. In H. M. Sohn \& J. Haig (Eds.), Japanese and Korean Linguistics, 6 (pp. 381-397). Stanford: CSLI Publications.

Schwarzschild, R. (1990). On the meaning of definite plural noun phrases. PhD dissertation, University of Massachusetts at Amherst.

Schwarzschild, R. (2002). The grammar of measurement. In B. Jackson (Ed.), Proceedings of semantics and linguistics theory, 12 (pp. 225-245). Ithaca: Cornell University.

Schwarzschild, R., \& Wilkinson, K. (2002). Quantifiers in comparatives: A semantics of degree based on intervals. Natural Language Semantics, 10, 1-41.

Seiter, W. (1979). Instrumental advancement in Niuean. Linguistic Inquiry, 10, 595-622.

Selkirk, E., \& Tateishi, K. (1991). Syntax and downstep in Japanese. In C. Georgopoulos \& R. Ishihara (Eds.), Interdisciplinary approaches to language: Essays in honor of S. - Y. Kuroda (pp. 519-543). Dordrecht: Kluwer

Sportiche, D. (1988). A theory of floating quantifiers and its corollaries for constituent structure. Linguistic Inquiry, 19, 425-449.

Takami, K. (1998). Nihongo-no suuryooshiyuuri-ni tsuite: Kinooronteki bunseki. Gengo, 27(1), 86-95; (2) 86-95; (3) 98-107.

Terada, M. (1990). Incorporation and argument structure in Japanese. $\mathrm{PhD}$ dissertation, University of Massachusetts at Amherst.

Verkuyl, H. (1981). Numerals and quantifiers in X-bar-syntax and their semantic interpretation. In J. Groenendijk et al. (Eds.), Formal methods in the study of language (pp. 567-599). Amsterdam: Mathematisch Centrum.

Yang, R. (2001). Common nouns, classifiers, and quantification in Chinese. PhD dissertation, Rutgers University. 